\title{
The implementation and effectiveness of the one stop centre model for intimate partner and sexual violence in low- and middle-income countries: a systematic review of barriers and enablers
}

\author{
Rose McKeon Olson (D) ,' Claudia García-Moreno, ${ }^{2}$ Manuela Colombini ${ }^{3}$
}

To cite: Olson RMcK, García-Moreno C, Colombini M. The implementation and effectiveness of the one stop centre model for intimate partner and sexual violence in low- and middle-income countries: a systematic review of barriers and enablers. BMJ Global Health 2020;5:e001883. doi:10.1136/ bmjgh-2019-001883

Handling editor Seye Abimbola

- Additional material is published online only. To view please visit the journal online (http://dx.doi.org/10.1136/ bmjgh-2019-001883).

Received 31 July 2019 Revised 7 February 2020 Accepted 15 February 2020

Check for updates

C Author(s) (or their employer(s)) 2020. Re-use permitted under CC BY-NC. No commercial re-use. See rights and permissions. Published by BMJ.

For numbered affiliations see end of article.

Correspondence to Dr Rose McKeon Olson; rose.mckeon.olson@gmail.com

\section{ABSTRACT}

Introduction Many low- and middle-income countries have implemented health-system based one stop centres to respond to intimate partner violence (IPV) and sexual violence. Despite its growing popularity in low- and middle-income countries and among donors, no studies have systematically reviewed the one stop centre. Using a thematic synthesis approach, this systematic review aims to identify enablers and barriers to implementation of the one stop centre (OSC) model and to achieving its intended results for women survivors of violence in low- and middle-income countries.

Methods We searched PubMed, CINAHL and Embase databases and grey literature using a predetermined search strategy to identify all relevant qualitative, quantitative and mixed methods studies. Overall, 42 studies were included from 24 low- and middle-income countries. We used a three-stage thematic synthesis methodology to synthesise the qualitative evidence, and we used the CERQual (Confidence in the Evidence from Reviews of Qualitative Research) approach to assess confidence in the qualitative research. Meta-analysis could not be performed due heterogeneity in results and outcome measures. Quantitative data are presented by individual study characteristics and outcomes, and key findings are incorporated into the qualitative thematic framework.

Results The review found 15 barriers with highconfidence evidence and identified seven enablers with moderate-confidence evidence. These include barriers to implementation such as lack of multisectoral staff and private consultation space as well as barriers to achieving the intended result of multisectoral coordination due to fragmented services and unclear responsibilities of implementing partners. There were also differences between enablers and barriers of various OSC models such as the hospital-based OSC, the stand-alone OSC and the NGO-run OSC.

Conclusion This review demonstrates that there are several barriers that have often prevented the OSC model from being implemented as designed and achieving the intended result of providing high quality, accessible,

\section{Key questions}

What is already known?

- Several process evaluations of the one stop centre (OSC) model in low- and middle-income country (LMIC) settings have documented various challenges, enablers and lessons learnt.

- Important evaluation findings of OSCs are scattered across the published literature and in unpublished technical reports.

- Only one outcome evaluation has been published which reported that the OSC model led to increased short-term utilisation of primary health services.

- Despite increasing popularity of the OSC model in LMICs and among funders, no studies have evaluated the effectiveness of the OSC model in meeting survivor needs.

- No systematic review or evidence-based synthesis on the OSC model has been performed prior to the present study.

What are the new findings?

- The review found 15 high-confidence evidence barriers to implementation of the OSC model and to achieving its intended results. These included barriers to implementation such as staff time constraints and lack of basic medical supplies, which lead to barriers to achieving intended results like accessible care due to long wait times and out-of-pocket fees.

- The review also identified seven enablers with moderate-confidence evidence. These included enablers to implementation such as standardised policies and procedures. They also included enablers to achieving intended results, such as regular interagency meetings that facilitated increased multisectoral coordination.

acceptable, multisectoral care. Existing OSCs will likely require strategic investment to address these specific barriers before they can achieve their ultimate goal of reducing survivor retraumatisation when seeking care. 


\section{Key questions}

What do the new findings imply?

- The results of this review provide essential evidence to guide OSC leadership, funders, policymakers and government officials on specific factors that should be optimised in order for OSCs to be implemented as intended, achieve their intended results and reach their ultimate goal-namely, to reduce victim retraumatisation when seeking care.

- These data should be used to prioritise and guide investment, as well as inform more rigorous evaluation of existing OSCs prior to further promotion and scale-up of this model in LMICs.

More rigorous and systematic evaluation of the OSC model is needed to better understand whether the OSC model of care is improving support for survivors of IPV and sexual violence.

The systematic review protocol was registered and is available online (PROSPERO: CRD42018083988).

\section{INTRODUCTION}

Violence against women (VAW) is associated with harmful health consequences ${ }^{12}$ and is a major public health concern. ${ }^{3}$ VAW is also a barrier to achieving Sustainable Development Goal 5 on gender equality and women's empowerment, and Sustainable Development Goal 3 on health. ${ }^{4}$ The health sector is well situated to respond, as women facing violence are more likely to view health workers as trustworthy for disclosure of abuse and to use a variety of health services, including mental health, emergency department and primary care services when compared with non-abused women. ${ }^{5-8}$ A variety of one stop centre (OSC) models have emerged over the years that vary in structure and services provided, resulting in discussion as to how the OSC should be defined. For the purpose of this review, the authors defined an OSC model as an interprofessional, health-system based centre that provides survivor-centred health services alongside some combination of social, legal, police and/or shelter services to survivors of intimate partner violence (IPV) and/or sexual violence (SV).

The original OSC was developed in a tertiary hospital and aimed to provide acute services to survivors of violence. ${ }^{9}$ Soon after OSCs were established in Malaysia in 1994, the model was replicated throughout South East Asia and Western Pacific regions. ${ }^{9} 10$ It has now been widely implemented with donor support in several African countries, ${ }^{11}$ and similar models are emerging in Latin America. ${ }^{13}$ The majority of OSCs are hospital-based, typically within tertiary care facilities, while others are standalone centres that provide basic health services on-site and refer for specialised and emergency services. ${ }^{14}$ Some OSCs are more strongly linked to the judicial system as in the case of the Thuthutzela centres in South Africa. They may be managed by the government, private sector, nongovernmental organisations (NGOs) or a combination. ${ }^{14}$

\section{Rationale for development of the OSC}

The development of the OSC model was a response to numerous issues identified by survivors and their advocates when seeking services in traditional (nonintegrated) healthcare, police and legal systems. Survivors often need several multidisciplinary services that are scattered in different locations. They frequently need to retell their stories of trauma each time they engage with a different service/sector which can contribute to secondary victimisation. The intended results of the OSC model are to increase accessibility, acceptability, quality and multisectoral coordination of care in order to reach the ultimate goal of reducing survivor retraumatisation when seeking care. ${ }^{15-17}$

\section{Current evidence of the OSC model}

While multiple process evaluations of the OSC model have been performed, no studies have examined the effectiveness of the OSC model. ${ }^{18-51}$ Only one outcome evaluation has been published, which found that the OSC model led to short-term increased utilisation of primary health services. ${ }^{13}$ No systematic reviews on the OSC model have been published.

\section{Theory of change of the OSC model}

The authors have provided a theory of change for the OSC model to serve as an analytical framework for the study findings (figure 1). The OSC model requires specific inputs such as multidisciplinary staff and private consultation rooms, which contribute to OSC outputs such as more services provided at one location and at all hours, and reduced survivor interviews. These contribute to OSC outcomes such as improved multisectoral coordination and improved quality of survivor-centred care. These outcomes contribute to the ultimate goal of the OSC to reduce survivor revictimisation when seeking care.

\section{Practical rationale of this review}

There has been increasing global implementation, scaling-up and donor investment in OSCs, despite a lack of rigorous evaluation of their implementation or their effectiveness. A meeting on this was organised by the WHO in June 2018 where experts discussed current evidence of the OSC model, contextual variations, as well as its strengths and limitations. It was recommended that a systematic review be performed to better assess the barriers and enablers to OSC implementation and achieving its intended results, and to inform a framework for more systematic evaluations of OSCs.

\section{Review objective}

Using a thematic synthesis approach, this systematic review aims to identify enablers and barriers to implementation of the OSC model and to achieving its intended results for women survivors of violence in lowand middle-income countries (LMICs). 


\section{Theory of Change of the OSC model}
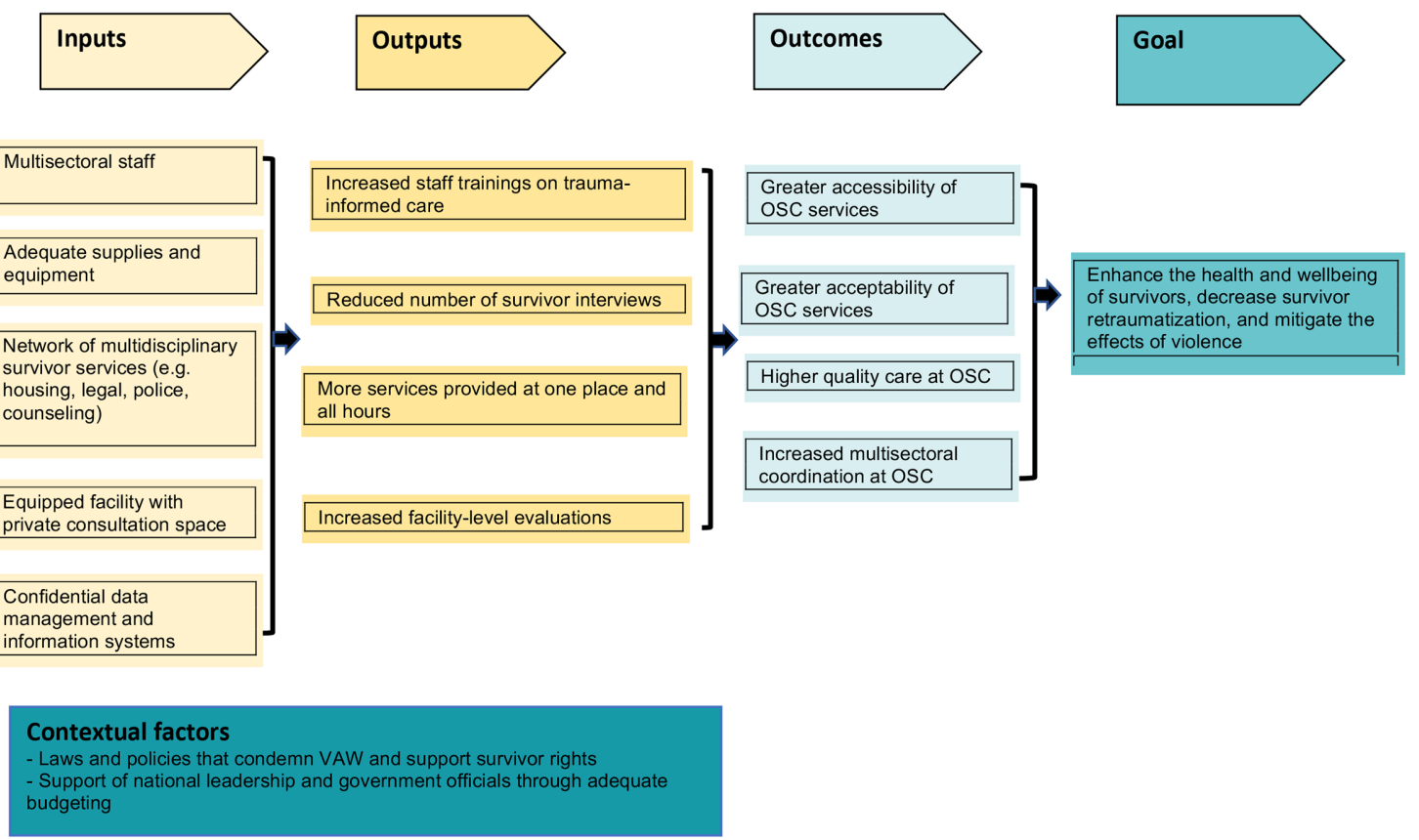

Figure 1 Theory of change of the OSC model.OSC, one stop centre; VAW, violence against women.

\section{METHODS}

\section{Patient and public involvement}

Patient/survivor experiences, preferences and priorities were sought in every step of the systematic review process. While perspectives of all stakeholders of the OSC model were included in the review, survivor experiences were specially desired and sought after during study selection and data extraction, as it was felt survivors could best inform how implementation of the OSC was affecting its beneficiaries (the survivors) and how the barriers and enablers were perceived to be meeting survivor needs. Patients/survivors themselves were not involved in the design or conduct of this systematic review.

\section{Search strategy}

Published literature was searched in PubMed, CINAHL and Embase using controlled vocabulary and free-text terms combining three main search elements: (a) partner violence and/or sexual violence, (b) one stop centre and (c) LMIC. Examples of IPV and/or sexual violence search terms include, 'Rape' (Mesh) OR 'Intimate Partner Violence'(Mesh) OR 'Domestic Violence'(Mesh). Examples of one-stop centre search terms include centre(tiab) OR centre(tiab) OR one stop(tiab) OR stand alone(tiab) OR protection unit(tiab). Full search strategies are available in online supplementary tables S1-3. The third search element was the LMIC context, which was used via the Cochrane Effective Practice and Organisation of Care (EPOC) Group LMIC filter (http:/ / epoc.-cochrane.org/ lmic-filters). Numerous combinations of these search elements were identified through thesaurus and Medical Subject Headings terms. The following databases were searched for additional studies, including grey literature and unpublished reports: WHO Global Health Library, Cochrane Library, Database of Abstracts of Reviews of Effects, Google Scholar, Centre for Reviews and Dissemination Database, OpenGrey and EThOS. Searches were conducted from 31 June 2018 to 31 December 2018. The search strategies were reviewed by two expert librarians. Numerous researchers in relevant fields were contacted to identify additional published and unpublished studies.

\section{Study selection}

All titles and abstracts identified were independently screened using a standardised form (RMO, CG-M). Each full-text article was reviewed by RMO, and in consultation with CG-M, pre-determined inclusion and exclusion criteria were applied (see table 1). The Preferred Reporting Items for Systematic Reviews and Meta-Analyses

\begin{tabular}{ll}
\hline Table 1 Criteria for inclusion and exclusion \\
\hline Inclusion criteria & Exclusion criteria \\
\hline $\begin{array}{l}\text { Uses quantitative, qualitative or } \\
\text { mixed method study designs }\end{array}$ & $\begin{array}{l}\text { Does not present primary } \\
\text { research }\end{array}$ \\
$\begin{array}{l}\text { Discusses the OSC model } \\
\text { Not published in English, } \\
\text { Spanish or French } \\
\text { language }\end{array}$ \\
$\begin{array}{ll}\text { Reports barriers and/or enablers } \\
\text { of the OSC model }\end{array}$ & $\begin{array}{l}\text { Full text is not available } \\
\text { Conducted in LMIC context }\end{array}$ \\
$\begin{array}{l}\text { Women were not } \\
\text { beneficiaries of the OSC } \\
\text { (eg, the OSC was only } \\
\text { for child survivors) }\end{array}$ \\
\hline
\end{tabular}

LMIC, low- and middle-income country; OSC, one stop centre. 
(PRISMA) diagram of search and study inclusion process is provided in online supplementary figure 1 . For the purposes of this review, the OSC was defined as any centre that provided integrated, multidisciplinary care to survivors of intimate partner and/or sexual violence with healthcare as a necessary component, as well as two or more additional on-site services, which could include any combination of social, legal and police services. For example, an integrated model that provided legal and police services was not considered an OSC, while a model that provided healthcare, shelter and legal services was considered an OSC. Any discrepancies in the screening were resolved through discussion and consultation with a third author (MC).

\section{Data extraction}

Data were extracted using a standardised form (online supplementary file $\mathrm{S} 1$ ). Themes, participant quotations and findings were extracted from qualitative studies, and where relevant, results and discussion sections of quantitative studies. Results and outcome measures were extracted from quantitative studies. Both types of data were extracted in the case of mixed methods studies.

\section{Synthesis}

A thematic synthesis methodology was used to analyse the qualitative data. ${ }^{52}$ The lead author (RMO) developed a spreadsheet of all qualitative data from the studies' findings sections, and where relevant, discussion sections. Using the three stage method outlined by Thomas and Harden, 2008, each relevant line of text was openly coded (RMO) through an inductive, line-by-line process to develop first-order themes, which were descriptive and similar in meaning to the primary studies. ${ }^{52}$ Based on the initial coding, 16 broad themes were developed, and through in iterative process, all text units were classified into one of the broad themes. Each theme was analysed further to develop the axial coding scheme and to disaggregate core themes. The text units were hand-sorted into first-order, second-order and third-order themes whereby axial codes were then systematically applied. Second-order themes were developed by grouping firstlevel themes together based on similarities and differences. Third-order themes were developed by grouping first-order and second-order themes together based on higher analytical themes. ${ }^{53}$ Enablers and barriers that emerged from quantitative studies were compared with qualitative themes and when appropriate, incorporated into the thematic analysis. For example, some quantitative studies found that provision of the full course of HIV pre-exposure prophylaxis (PEP) at first encounter improved PEP adherence rates. This result was felt to support the theme, 'minimisation of points of care facilitates medication adherence' and thus was referenced under this theme in the mixed method thematic synthesis.

\section{Quality assessment and confidence assessment}

The CERQual (Confidence in the Evidence from Reviews of Qualitative Research) approach was applied to each review finding to assess confidence in each review finding. ${ }^{54}$ The CERQual approach assesses how much confidence to place in review findings of qualitative systematic reviews based on: (1) methodological limitations, (2) relevance of the review question, (3) coherence and (4) adequacy of data. Methodological limitations were assessed using two tools: an adaptation of the Critical Appraisal Skills Programme (CASP) tool was used to assess the quality of the qualitative studies, ${ }^{55}$ and an adaptation of the Strengthening the Reporting of Observational Studies in Epidemiology (STROBE) statement was used to assess the quality of the quantitative studies. ${ }^{56}$ Examples of methodological limitations include unclear statement of aims, inappropriate recruitment strategy or lack of rigour in data analysis. No studies were excluded based on quality assessment, instead, methodological quality is reflected in the CERQual assessments. Each author independently assessed study quality using the CASP tool and STROBE checklist to qualitative and quantitative studies, respectively (online supplementary files S4 and S5). Using a pre-determined scoring template, each author applied each of the four CERQual criteria to each review finding (online supplementary file S6). After each of the quality assessments and four CERQual elements were evaluated, the CERQual level of confidence for each review finding was assigned as high, moderate or low (RMO, MC, CG-M). Discrepancies were resolved by discussion until consensus was reached among authors.

\section{Reporting}

This systematic review follows the Enhancing Transparency in Reporting the Synthesis of Qualitative Research (ENTREQ) statement guidelines (online supplementary file S2) ${ }^{57}$ It also follows the 2009 PRISMA guidelines (online supplementary file S3). ${ }^{58} 59$

\section{RESULTS}

Database searches identified 3529 potentially relevant articles. Thirty-eight published and unpublished reports were retrieved by contacting relevant researchers, for a total of 3567 potentially eligible studies. Of the 191 studies selected for full-text review, 42 studies met inclusion criteria (see figure 1). This systematic review presents primary research findings from 42 studies from 24 LMICs, including 15 countries in Asia and 9 countries in Africa (see table 2). Nineteen studies used qualitative methods, 8 studies used quantitative methods and 16 studies used mixed methods. In 17 studies, the respondents were OSC stakeholders, in 11 studies the respondents were survivors of IPV and/or $\mathrm{SV}$, in 12 studies the respondents were both OSC stakeholders and survivors and in 1 study the respondents were community members. ${ }^{46}$ OSC stakeholders included government officials in 14 studies, healthcare workers in 15 studies, OSC staff (other than healthcare workers) in 25 studies and police members in 6 studies. 


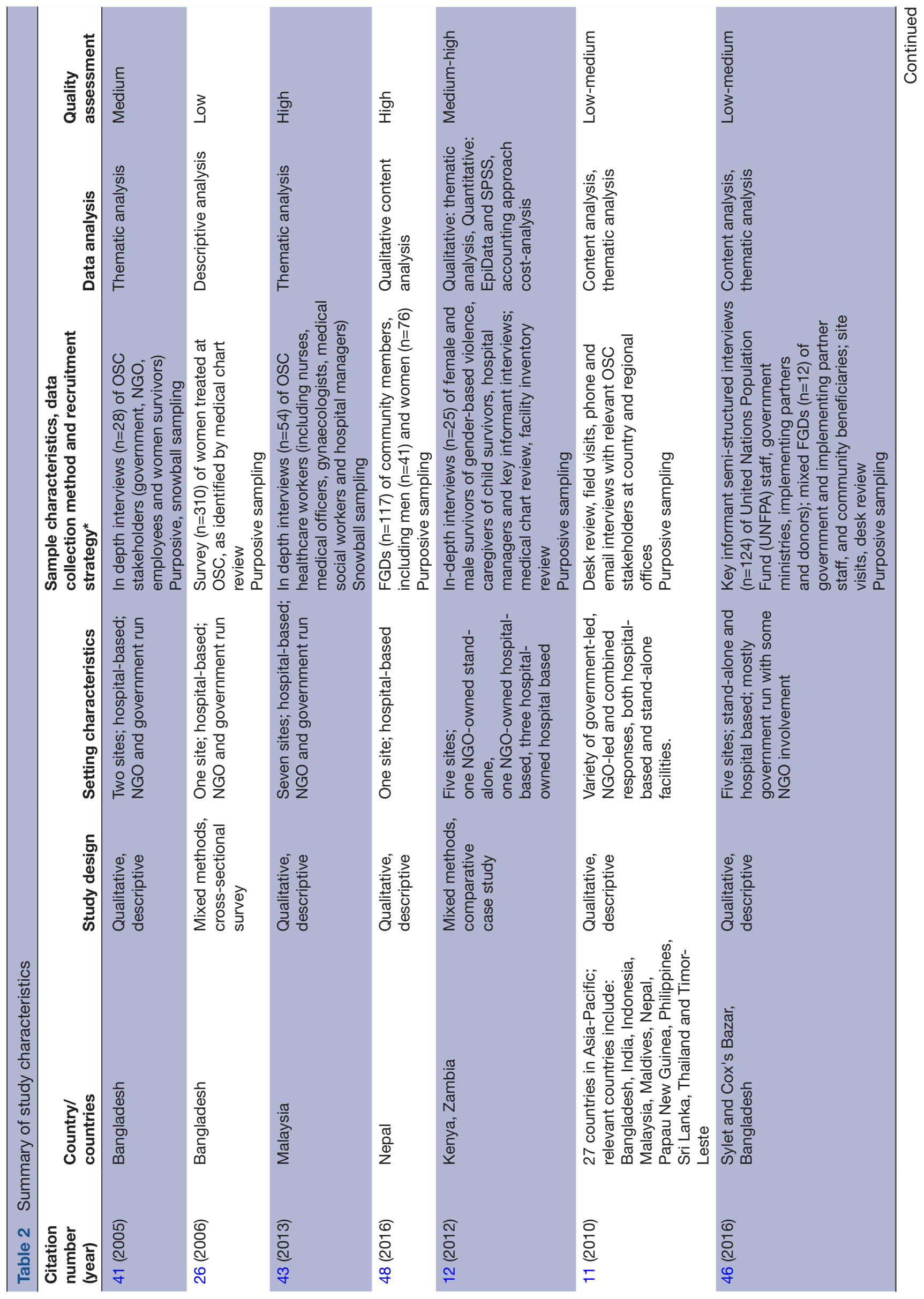

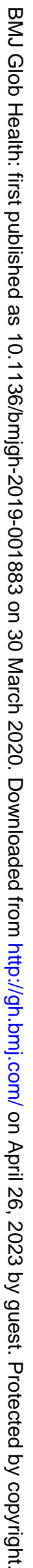




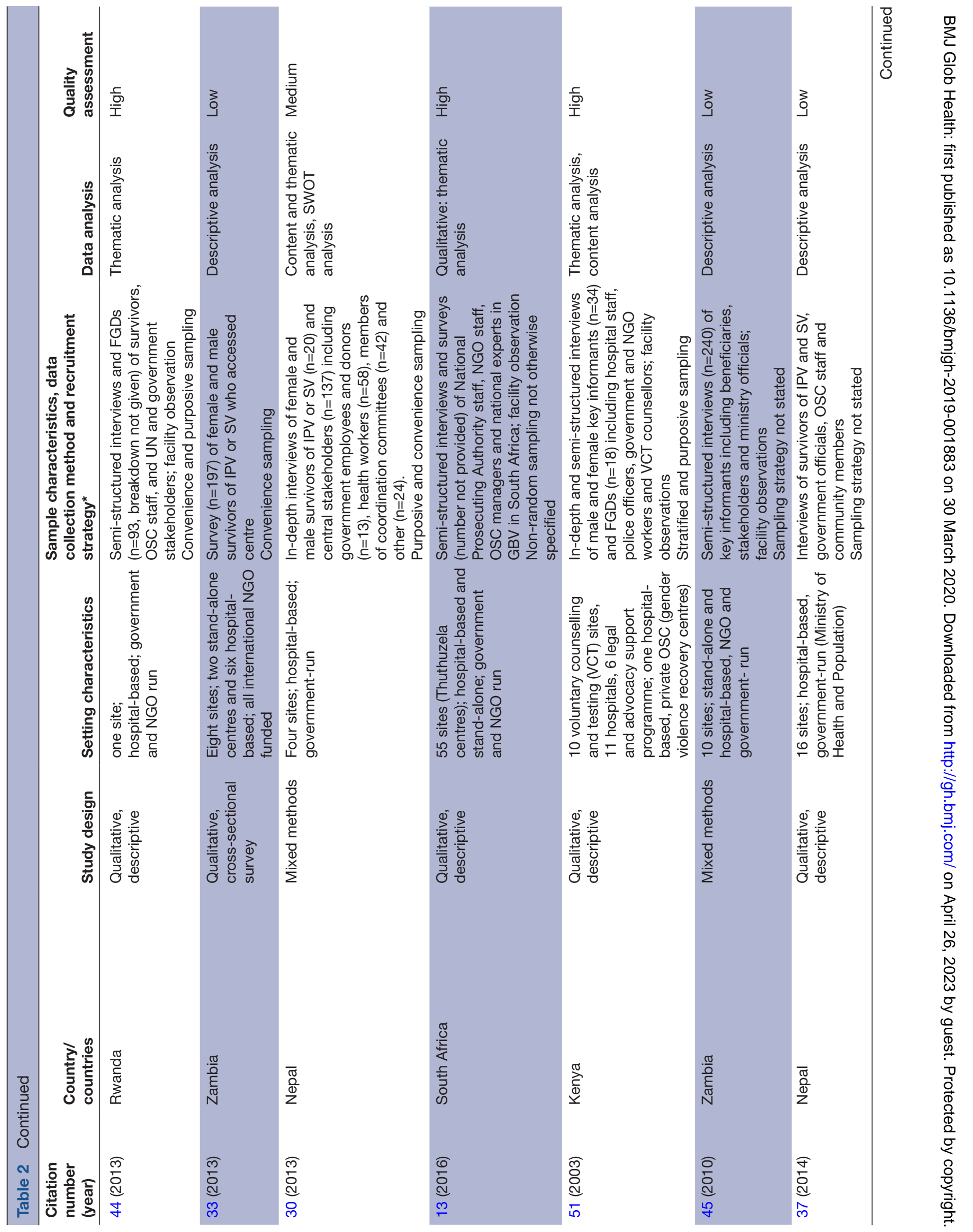




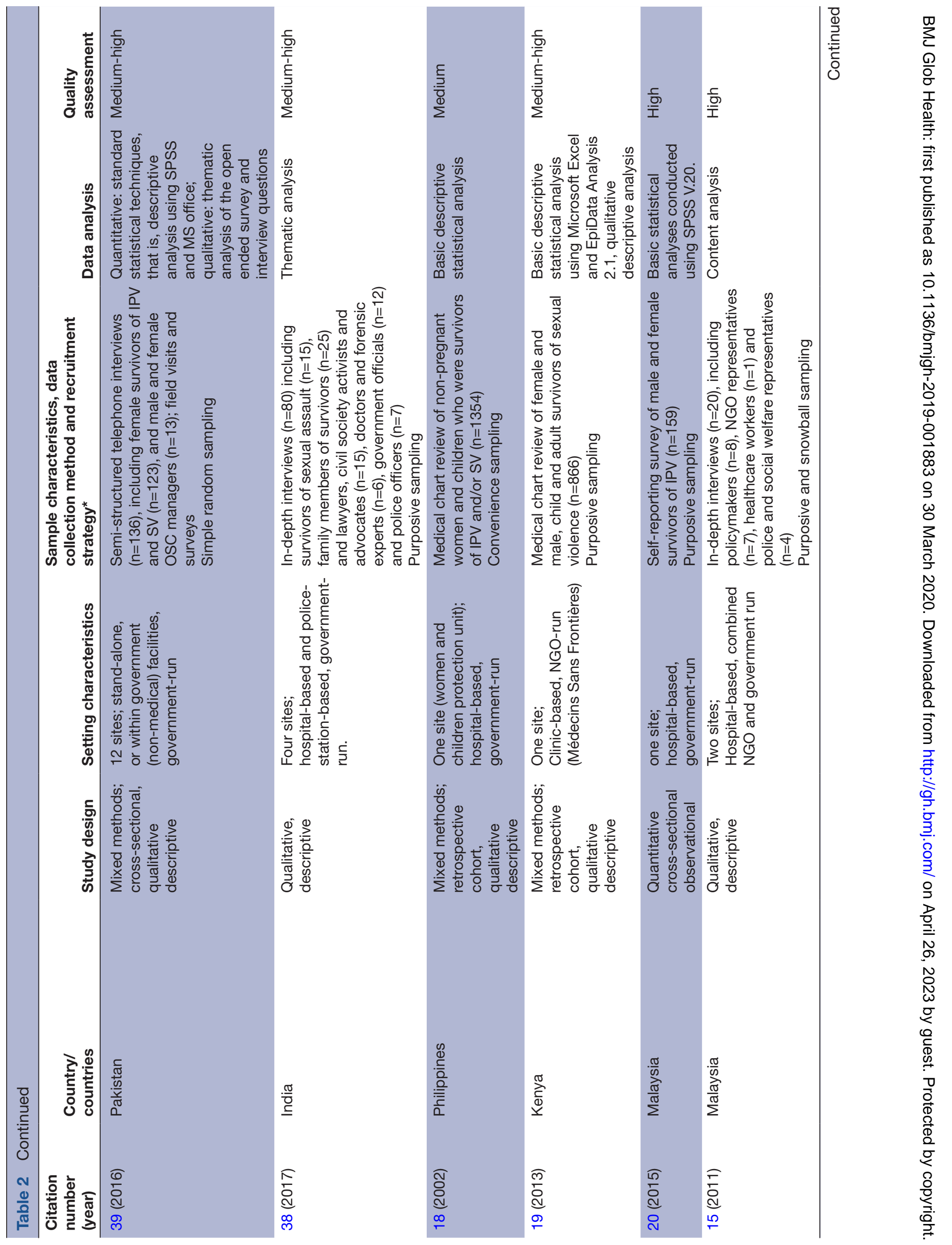




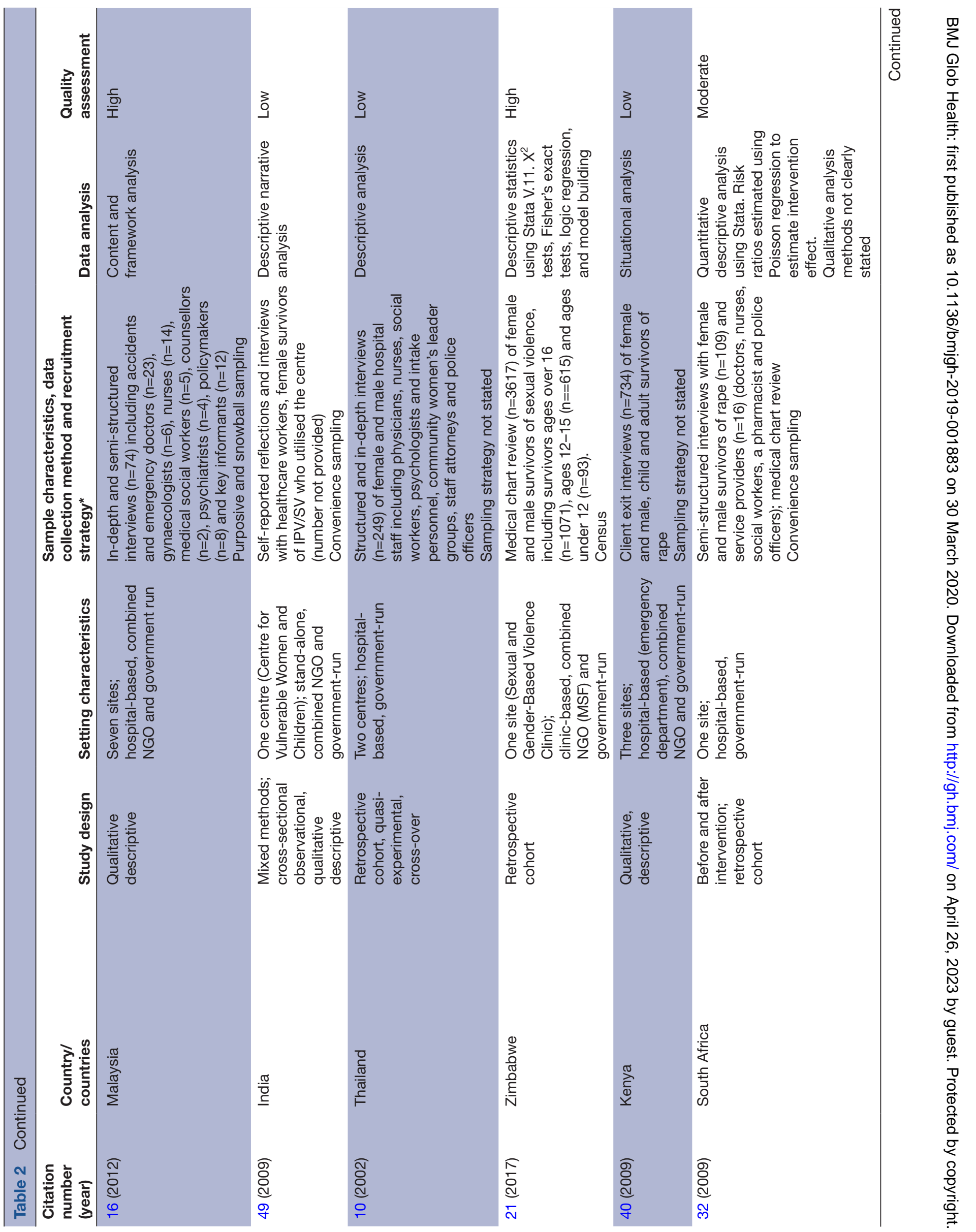




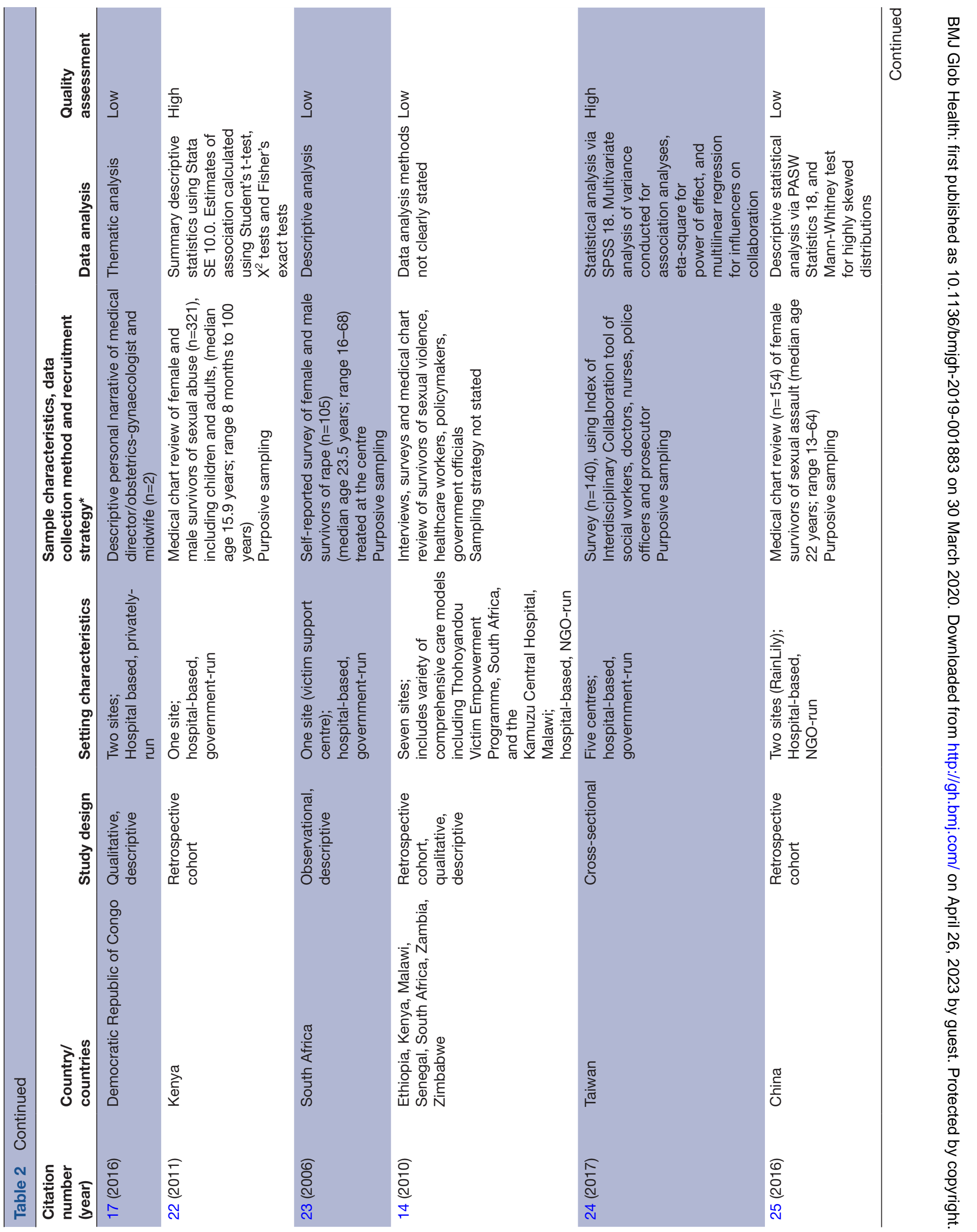




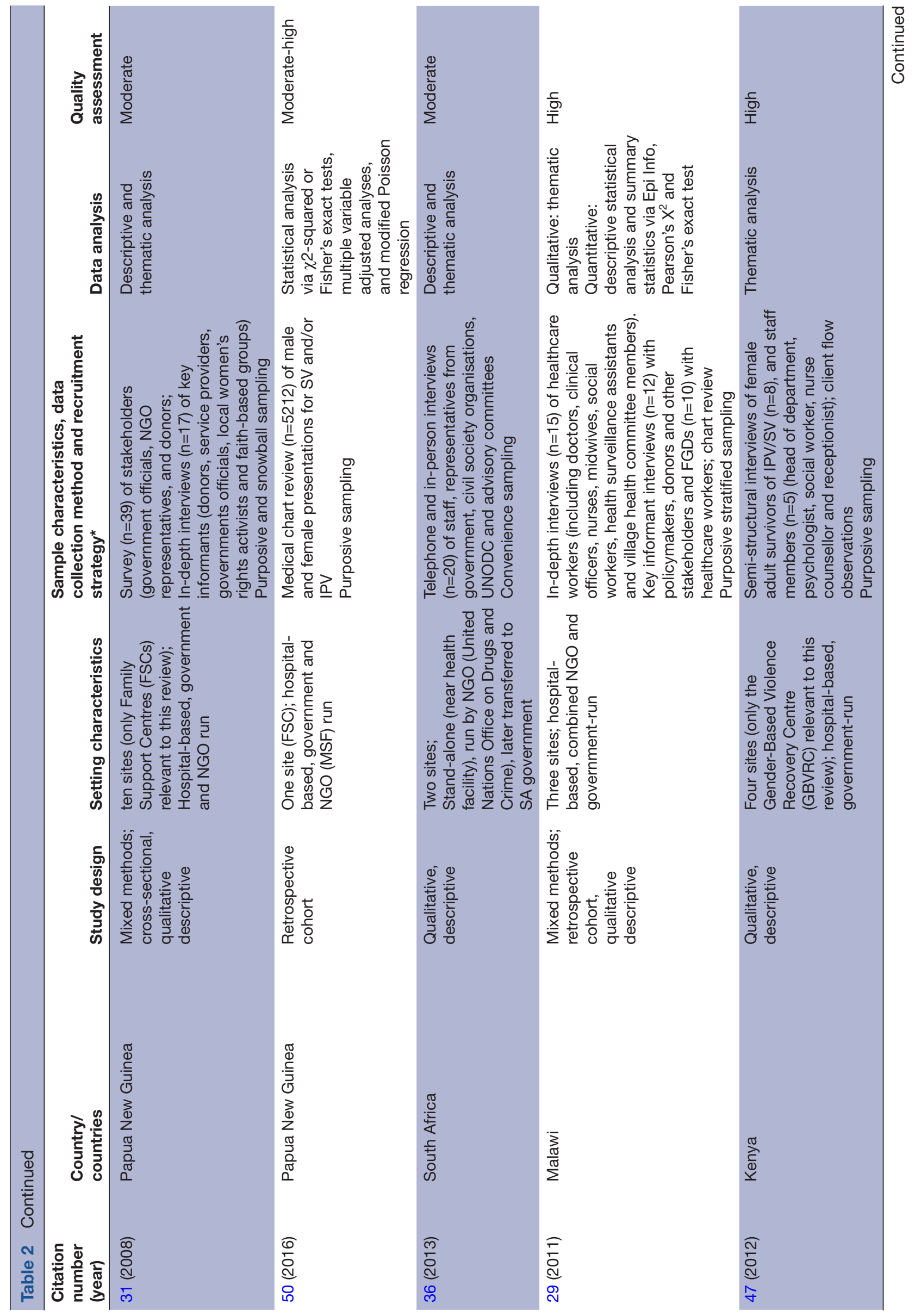

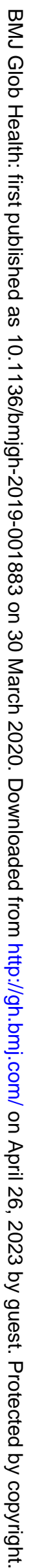




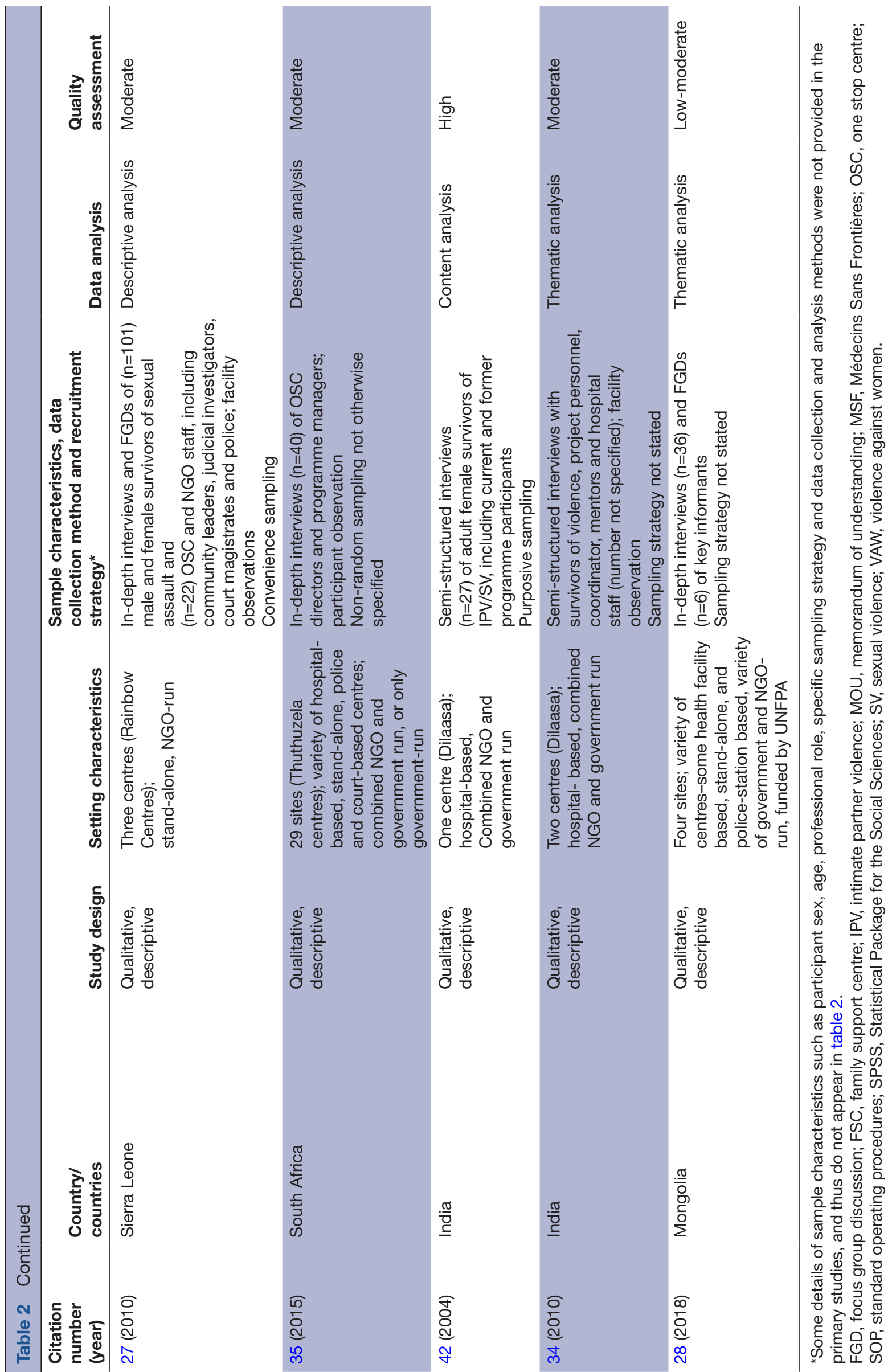

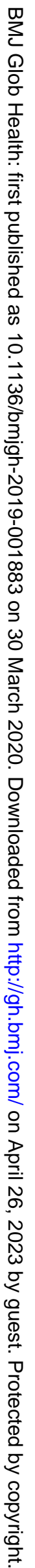


Table 3 Summary of quantitative study findings

\begin{tabular}{|c|c|c|c|}
\hline $\begin{array}{l}\text { Citation number } \\
\text { (year) }\end{array}$ & Key findings of enablers and barriers & $\begin{array}{l}\text { Quality } \\
\text { assessment }\end{array}$ & $\begin{array}{l}\text { Themes incorporated into qualitative } \\
\text { synthesis ( } E=\text { enabler, } B=\text { barrier) }\end{array}$ \\
\hline $18(2002)$ & $\begin{array}{l}\text { There was a delay from time of the abuse to presentation at the } \\
\text { OSC, which was attributed to the geographic inaccessibility of the } \\
\text { centre, especially for rural populations, as well as lack of community } \\
\text { awareness. Higher reporting of sexual abuse cases was attributed } \\
\text { to preference among women and children community members to } \\
\text { seek care from doctors who specialise in this care and can meet } \\
\text { survivor needs. }\end{array}$ & Medium & $\begin{array}{l}\text { B: Lack of access to rural populations } \\
\text { B: Lack of community awareness of OSC } \\
\text { services } \\
\text { F: Sensitive staff knowledge, attitudes and } \\
\text { behaviours }\end{array}$ \\
\hline $20(2015)$ & $\begin{array}{l}\text { There were weaknesses in OSC staff documentation and concerns } \\
\text { over survivor confidentiality. OSC staff had unclear roles and } \\
\text { responsibilities. Some of the OSC staff were found to have victim- } \\
\text { blaming attitudes, and many failed to provide necessary health } \\
\text { information to patients. Some staff did not provide rape survivors } \\
\text { with sensitive care and failed to spend time to console patients } \\
\text { after report of sexual assault. There was a lack of OSC staff training, } \\
\text { with more than half of the staff having never attended any training } \\
\text { sessions in OSC management even after some had worked for } \\
\text { years in the OSC. }\end{array}$ & High & $\begin{array}{l}\text { B: Poor documentation and data } \\
\text { management systems } \\
\text { B: Compromised confidentiality and } \\
\text { privacy } \\
\text { B: Unclear staff responsibilities and roles } \\
\text { B: Harmful staff attitudes } \\
\text { B: Harmful behaviours of health workers } \\
\text { B: Failure to provide health information } \\
\text { B: Inadequate training on trauma informed } \\
\text { care and OSC operations }\end{array}$ \\
\hline $21(2017)$ & $\begin{array}{l}\text { Follow-up was a common issue, and } 42 \% \text { or } 938 \text { survivors had no } \\
\text { follow-up }\end{array}$ & High & $\begin{array}{l}\text { B: Lack of long-term support and } \\
\text { follow-up }\end{array}$ \\
\hline $22(2011)$ & $\begin{array}{l}44 \% \text { of survivors were reported to receive counselling at the centre. } \\
\text { There was a lack of available psychosocial support, and only one } \\
\text { counsellor was available during standard business hours throughout } \\
\text { the duration of this study. There was a lack of support for survivors } \\
\text { who presented at night or on weekends. Another barrier was lack of } \\
\text { awareness of OSC services and support for women rape survivors } \\
\text { in the community. Clear protocols were noted to assist in improved } \\
\text { documentation at the centre. }\end{array}$ & High & $\begin{array}{l}\text { B: Lack of adequate psychosocial } \\
\text { services and staff } \\
\text { B: Lack of services on nights and } \\
\text { weekends } \\
\text { B: Lack of community awareness of OSC } \\
\text { services } \\
\text { F: Standardised policies and procedures }\end{array}$ \\
\hline $23(2006)$ & $\begin{array}{l}\text { There was a lack of survivor-centred care, with privacy concerns. } \\
\text { Survivors had to wait in their blood stained, dirty clothes until the } \\
\text { healthcare worker could examine them. There was also a lack of } \\
\text { provision of health information, such as STI, HIV and pregnancy risk } \\
\text { after sexual assault. Long waiting times were also a concern at the } \\
\text { hospital. }\end{array}$ & Low & $\begin{array}{l}\text { B: Compromised confidentiality and } \\
\text { privacy } \\
\text { B: Failure to provide health information } \\
\text { B: Long wait times }\end{array}$ \\
\hline 25 (2016) & $\begin{array}{l}\text { Follow-up attendance after the incident was } 57.8 \%, 63.6 \% \text {, } \\
59.1 \% \text { and } 46.8 \% \text { at } 2 \text { weeks, } 6 \text { weeks, } 3 \text { months and } 6 \text { months, } \\
\text { respectively. Overall, less than half of survivors returned for follow- } \\
\text { up visits. }\end{array}$ & Low & $\begin{array}{l}\text { B: Lack of long-term support and } \\
\text { follow-up }\end{array}$ \\
\hline
\end{tabular}

OSC, one stop centre; STI, sexually transmitted infections.

\section{Quantitative synthesis}

A total of eight studies with quantitative data had findings relevant to the review. ${ }^{18-25}$ Meta-analysis was not possible due to wide variations in study designs, measures and outcomes. Instead, descriptions of relevant findings from quantitative studies including data found in results and discussion sections are presented (table 3). Enablers and barriers that emerged from the quantitative studies are incorporated into the thematic synthesis.

\section{Qualitative synthesis}

Nineteen studies used qualitative methods and 16 used mixed methods. Perspectives varied by study, including survivors, staff and other stakeholders such as policymakers and donors (see S4 Table). Tables 4A,B presents the summary of study findings and the CERQual confidence assessments; table $4 \mathrm{~A}$ presents barriers and table $4 \mathrm{~B}$ presents enablers.

\section{Governance and leadership}

\section{Laws, policies and procedures}

Supportive laws and policies on violence against women gave OSCs legitimacy and generated high-level commitment from government officials (moderate confidence (MC) ). ${ }^{101126-28}$ Some OSCs that lacked standardised operating procedures (SOPs) struggled to provide consistently high-quality care (MC)..$^{101516283031}$ The implementation of many SOPs faced significant challenges due to lack of 


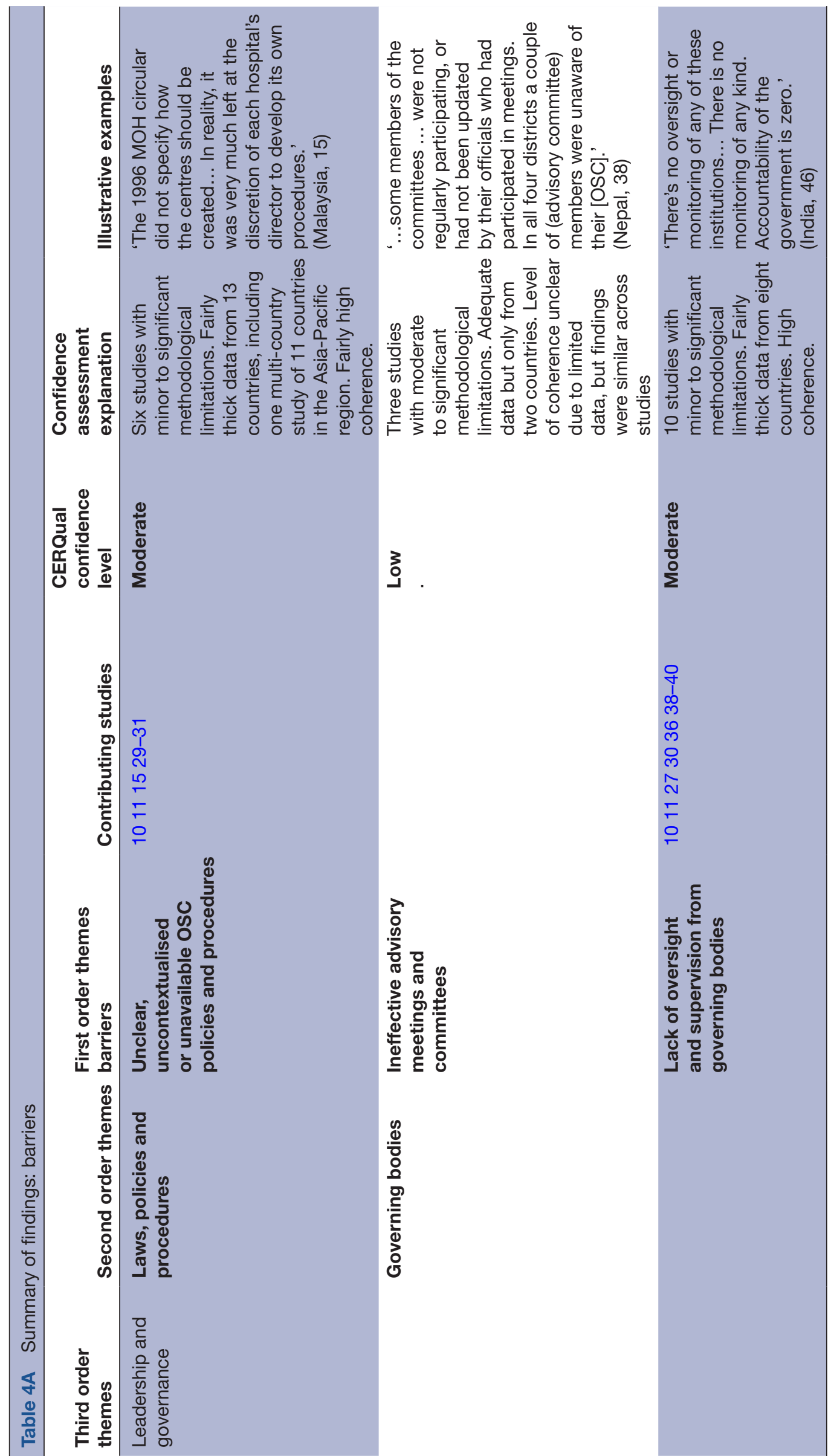




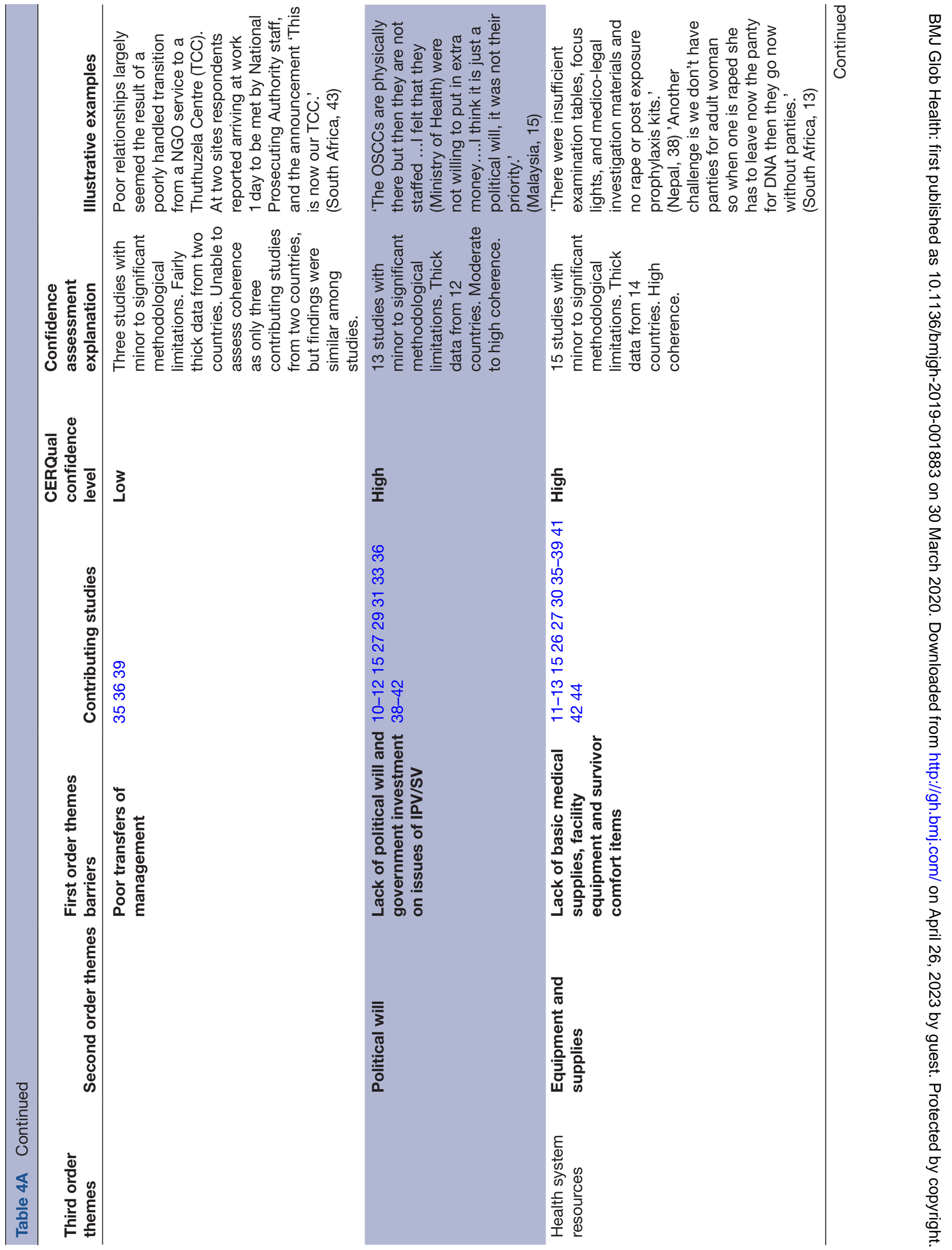




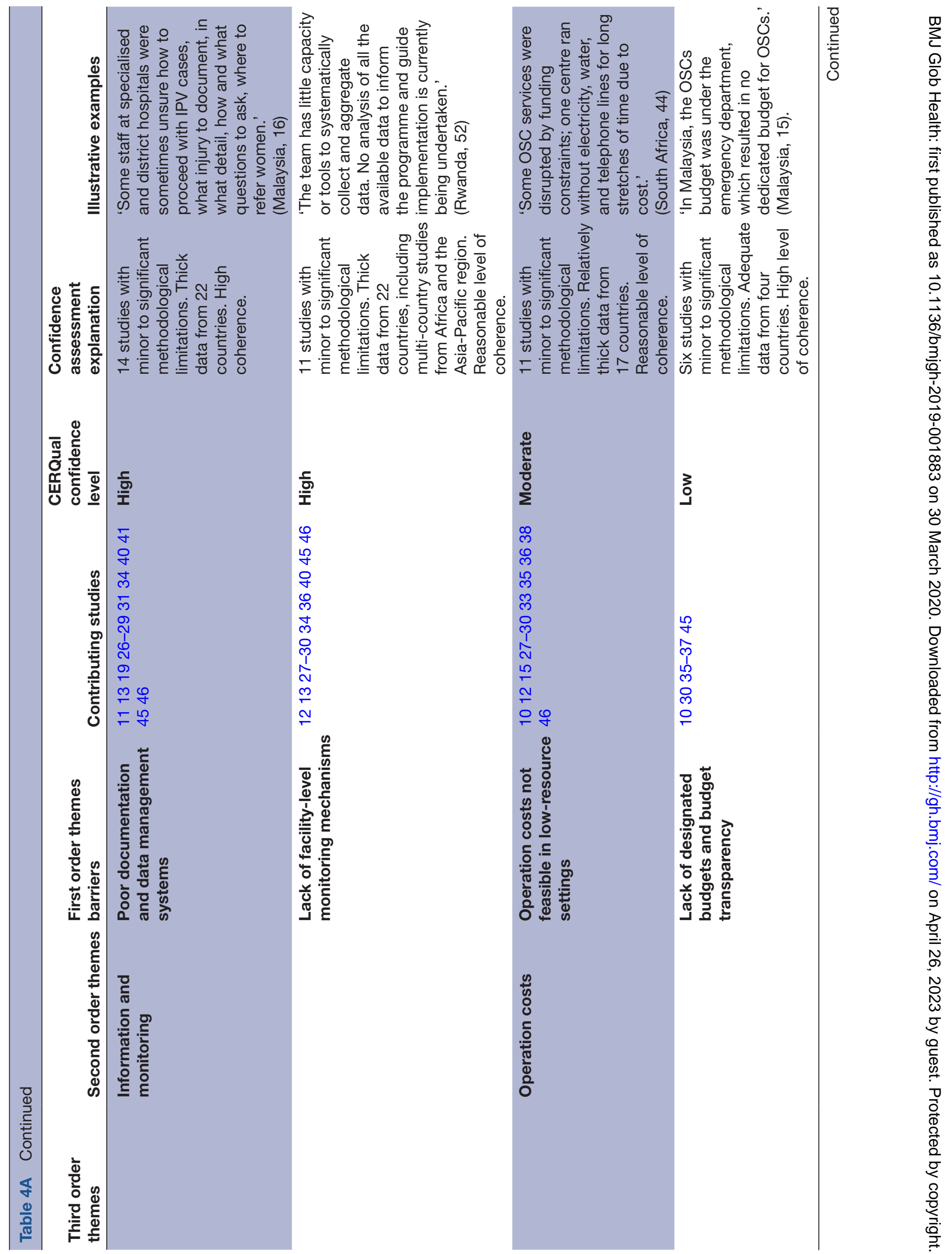




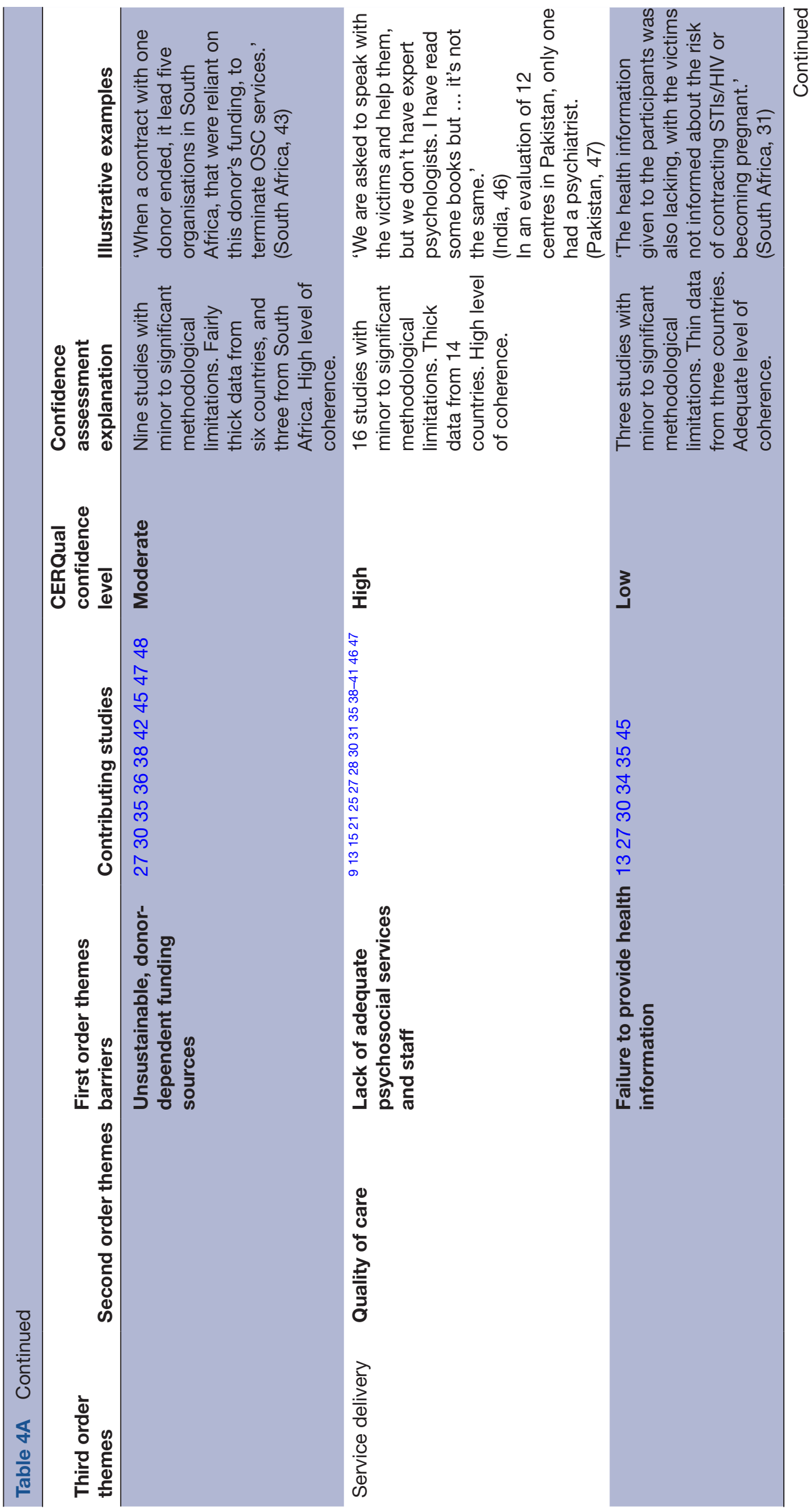

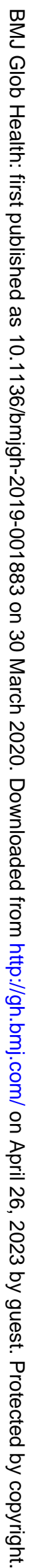


흠

3

움

$\infty$

ल

ल

ल

क़

N

กิ ใ

다

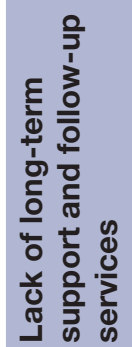

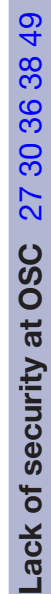

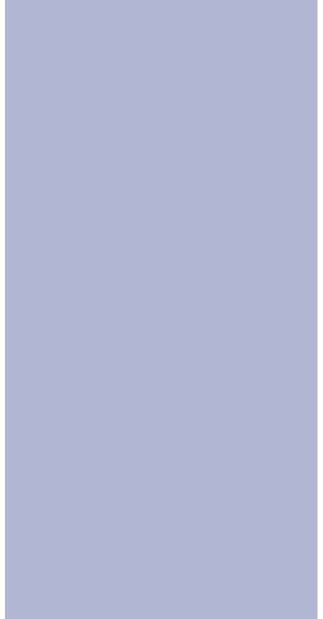




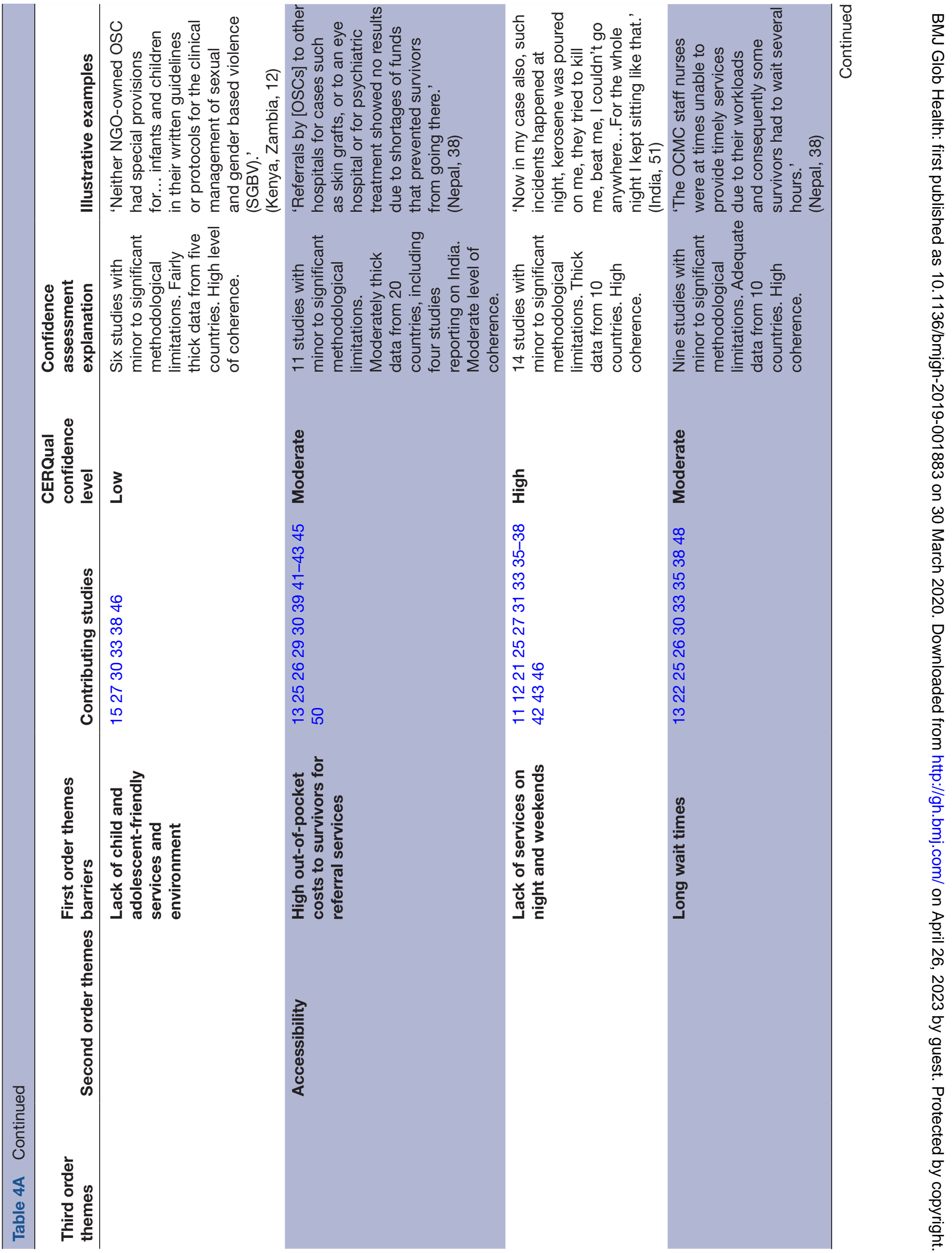




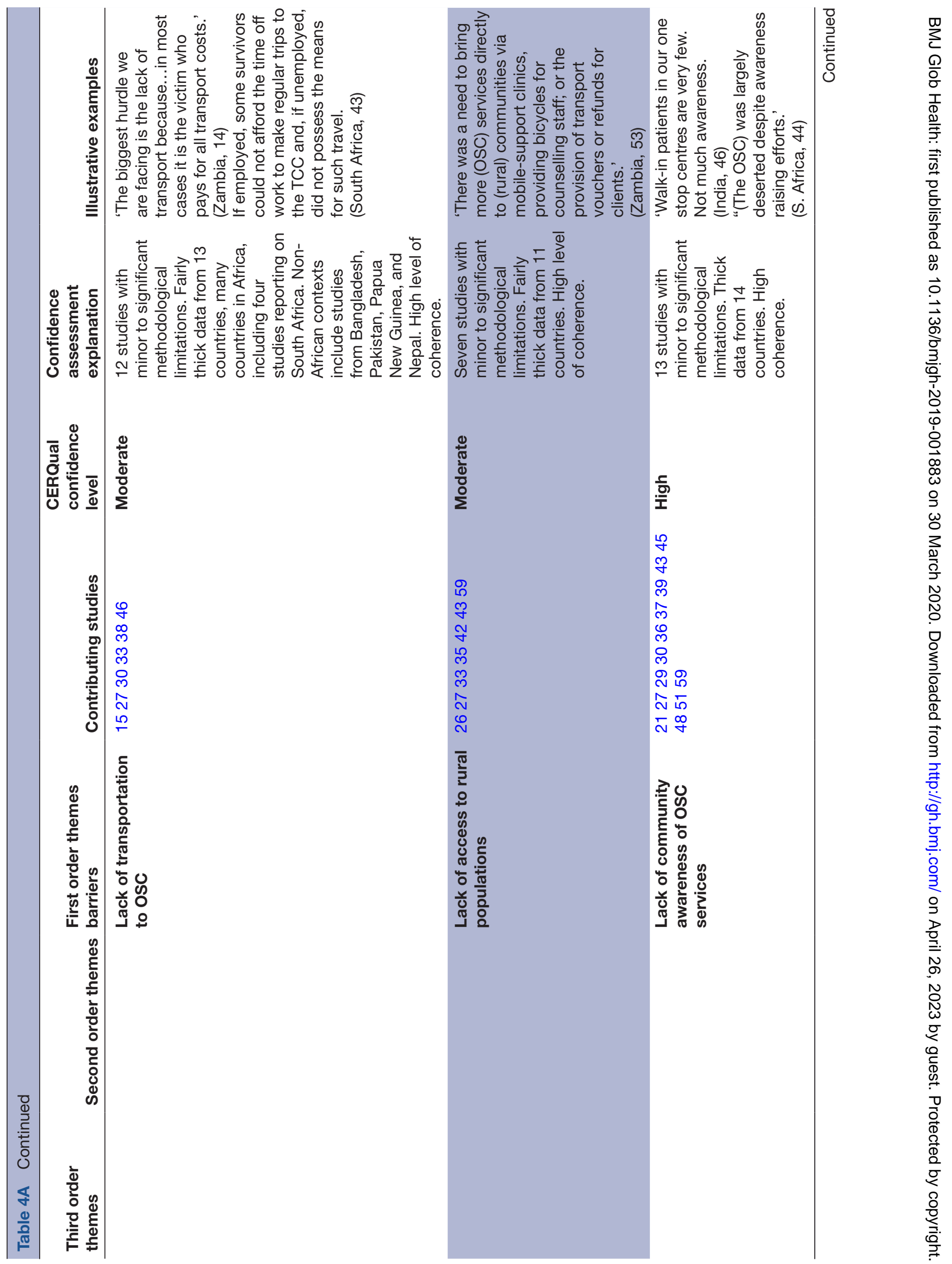




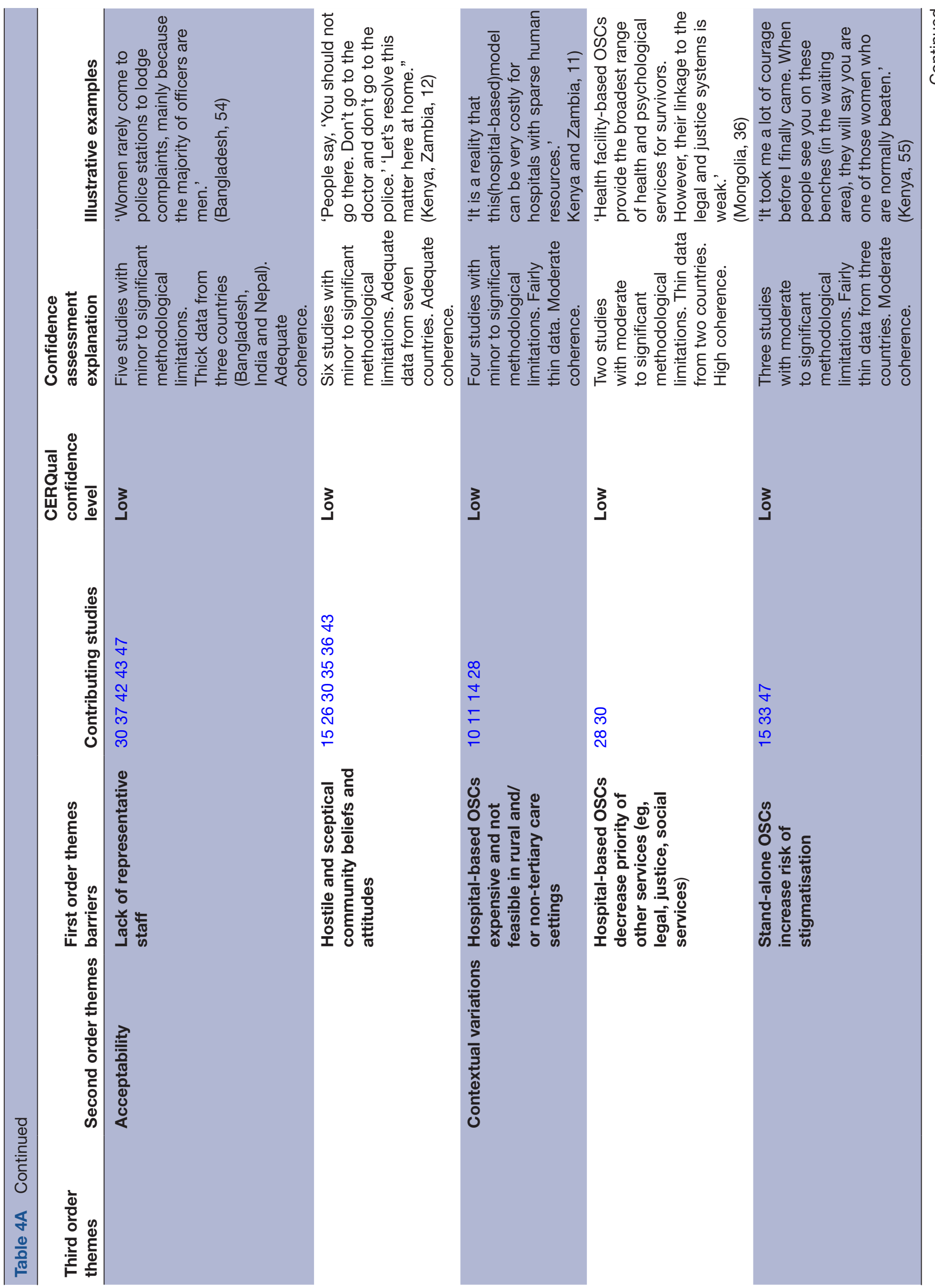

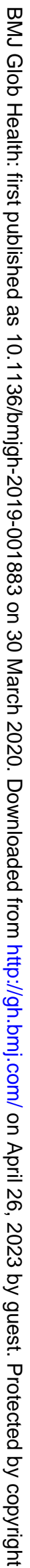




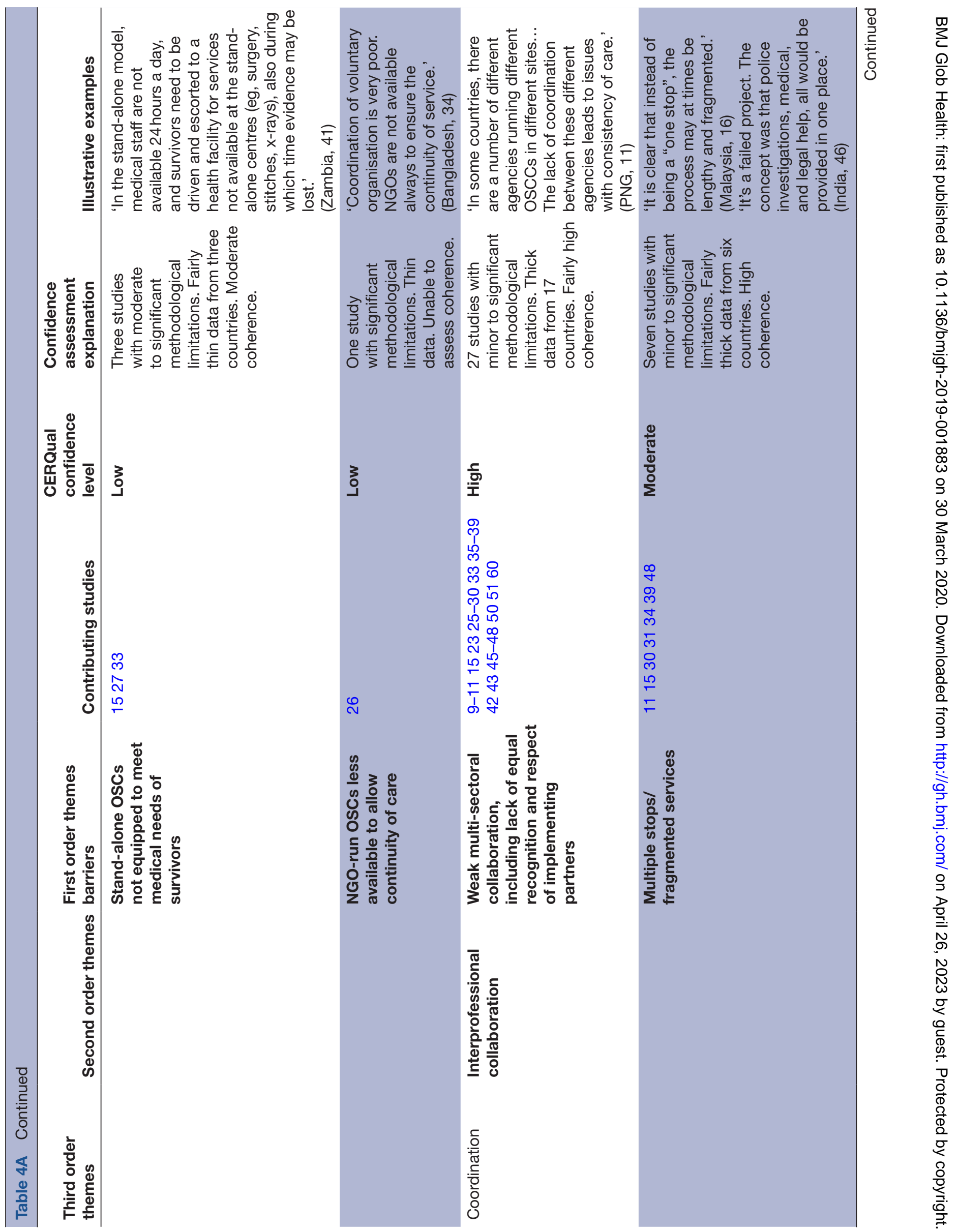




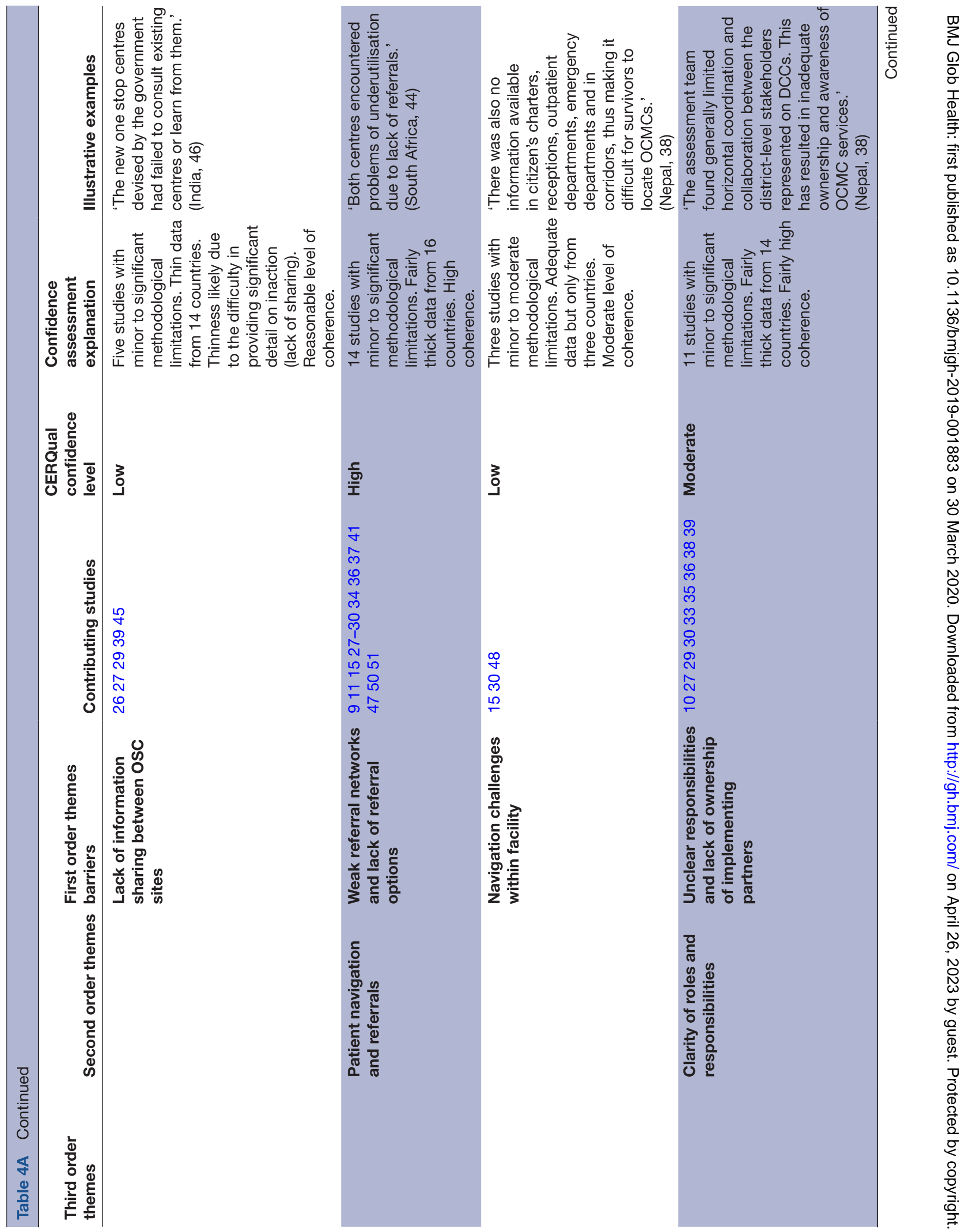




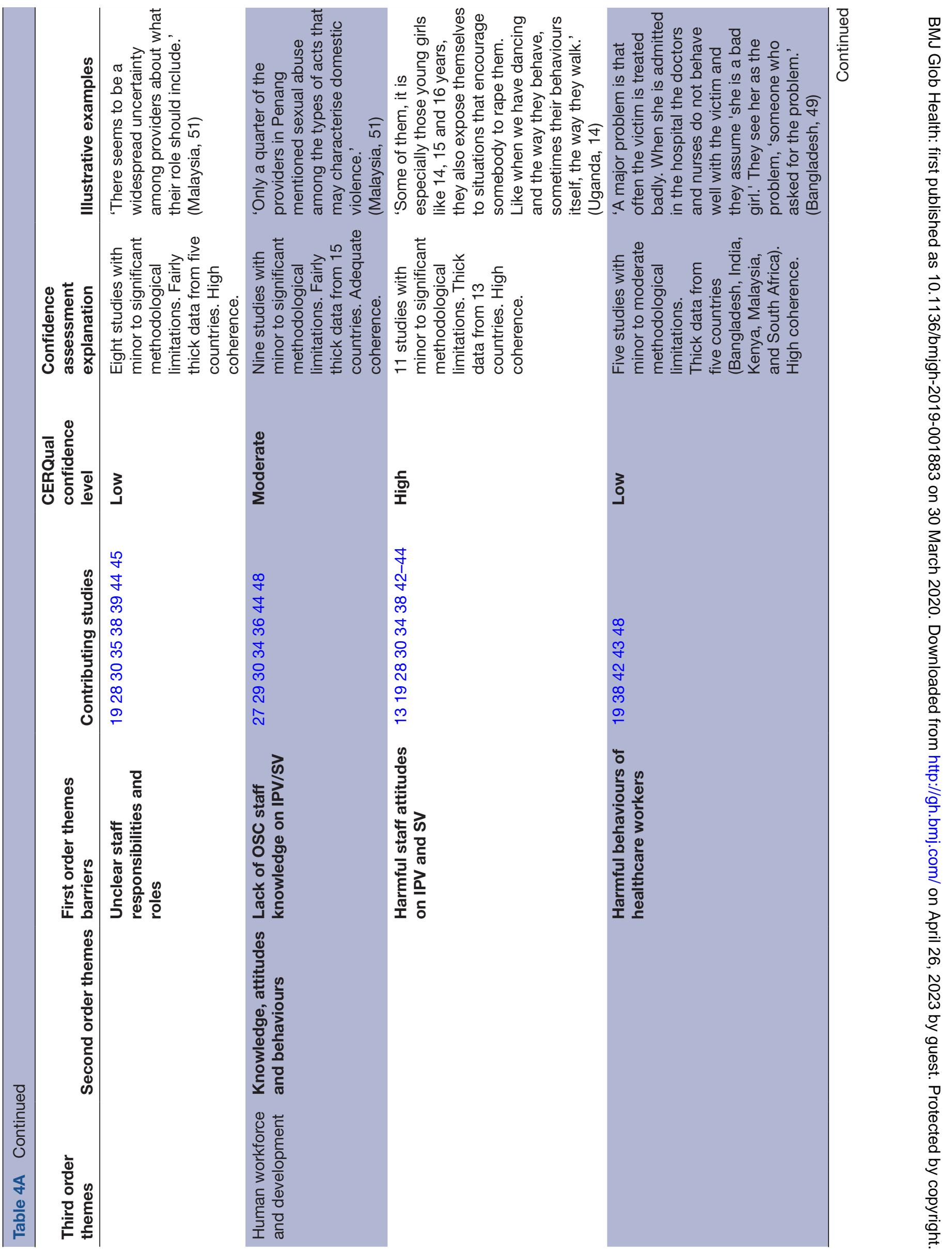




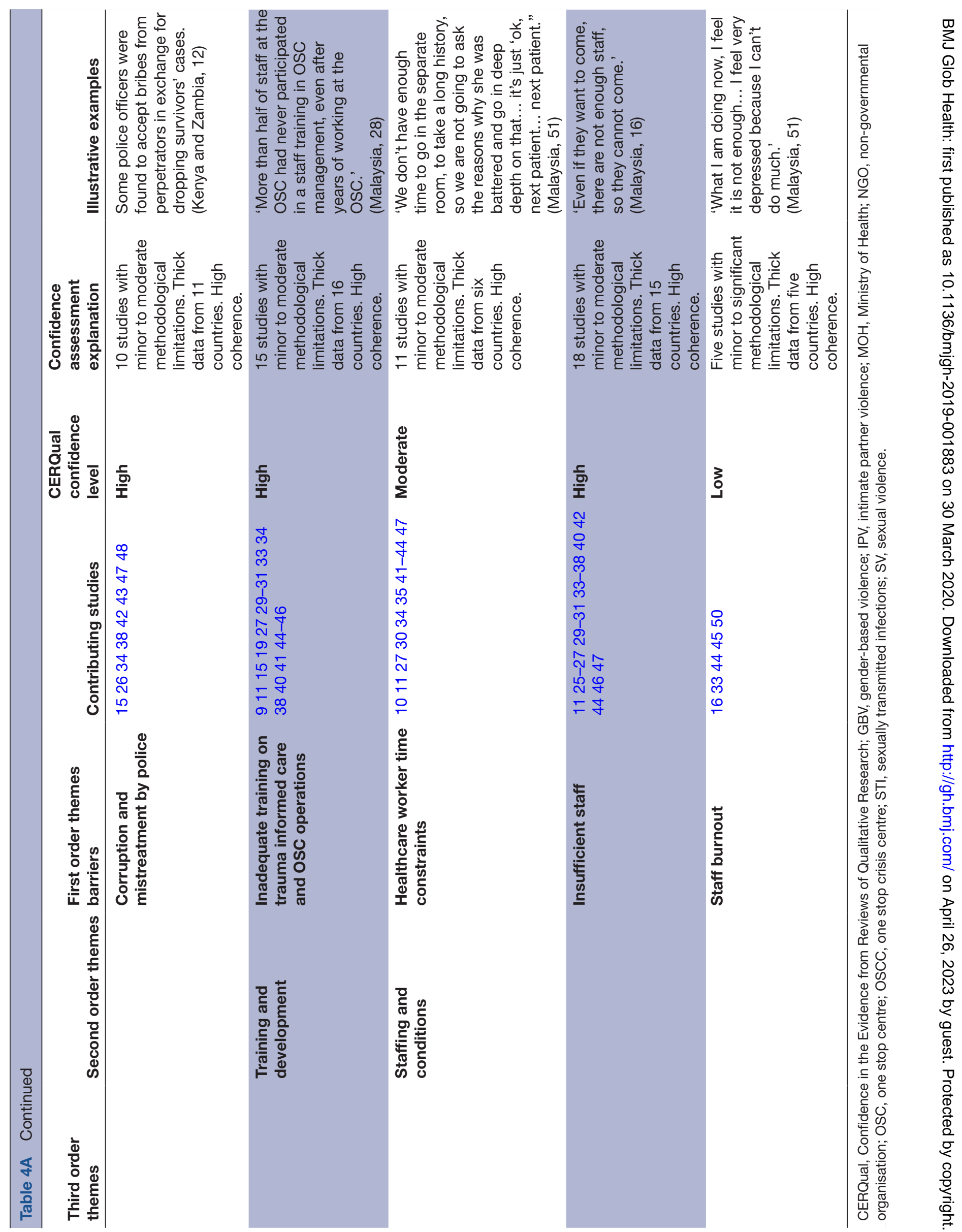




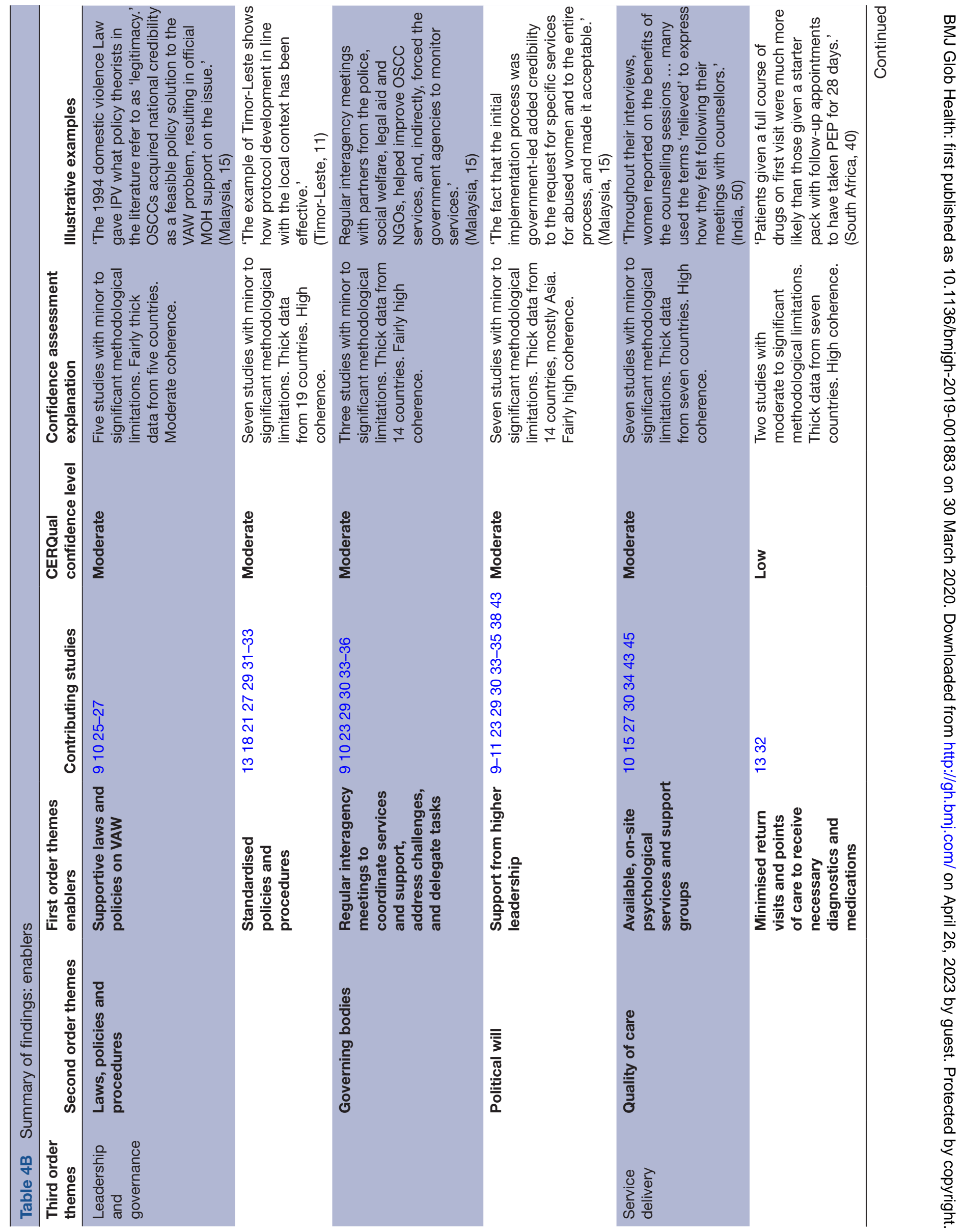




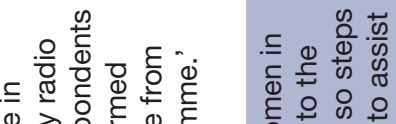

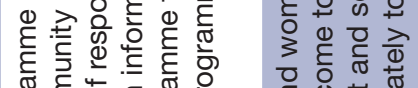
흘

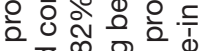

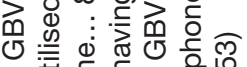

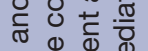

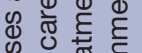

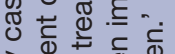
凹

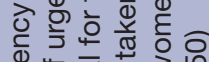
ㄴ. क्ञ

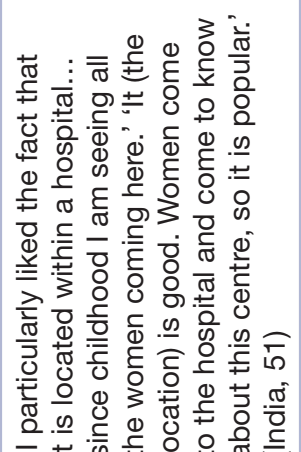

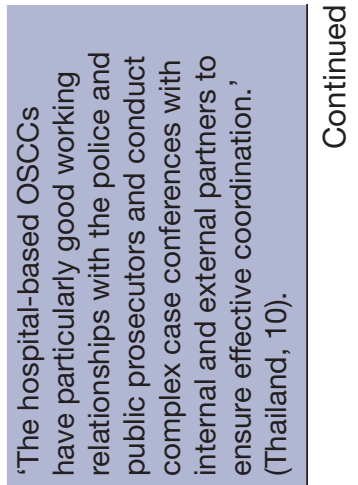

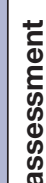

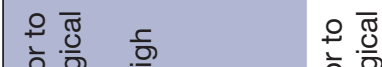

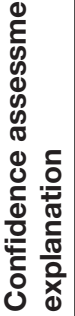

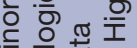

हो 융 흉

돈 은 은

o $\varepsilon F$

记 을

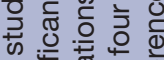

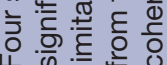

흘응 흥 흥

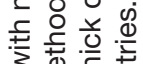

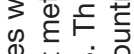

粞 步

कि 突

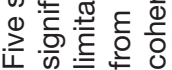

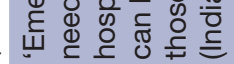

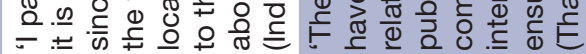

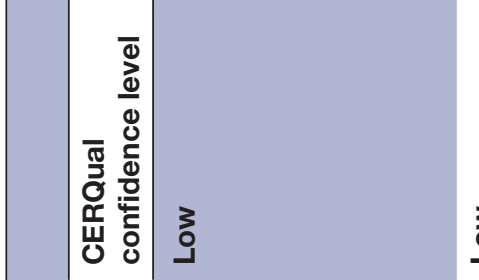

בั

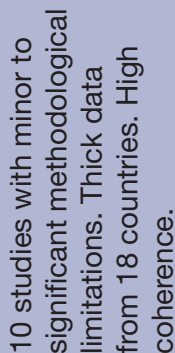

운흥
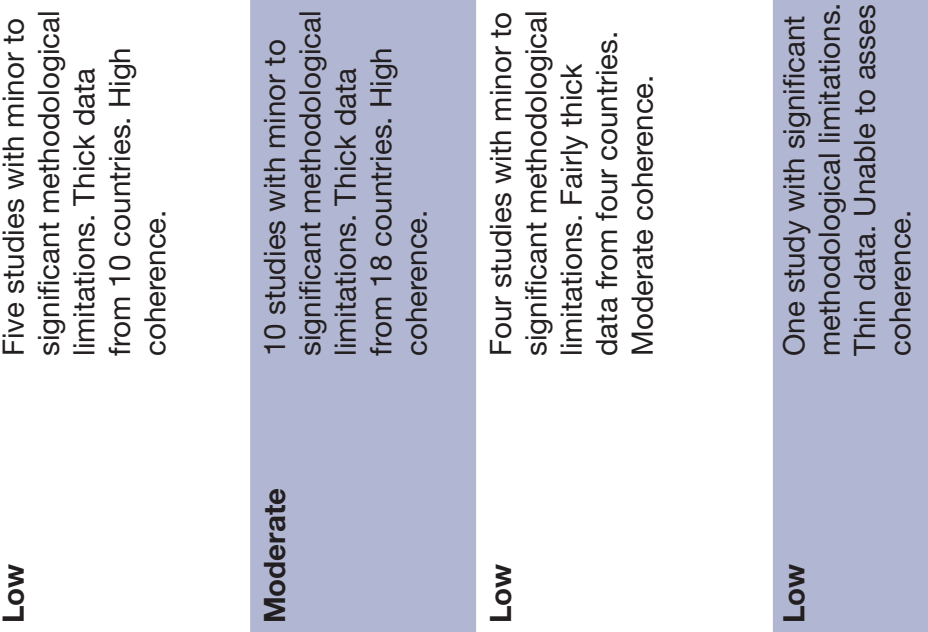

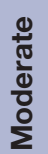

3

3

伯

๓ุ

色

0
+
के
+े
ले
ले
m

ले

$\infty$

న

in

ले

능 8

$\mp \mathscr{q}$
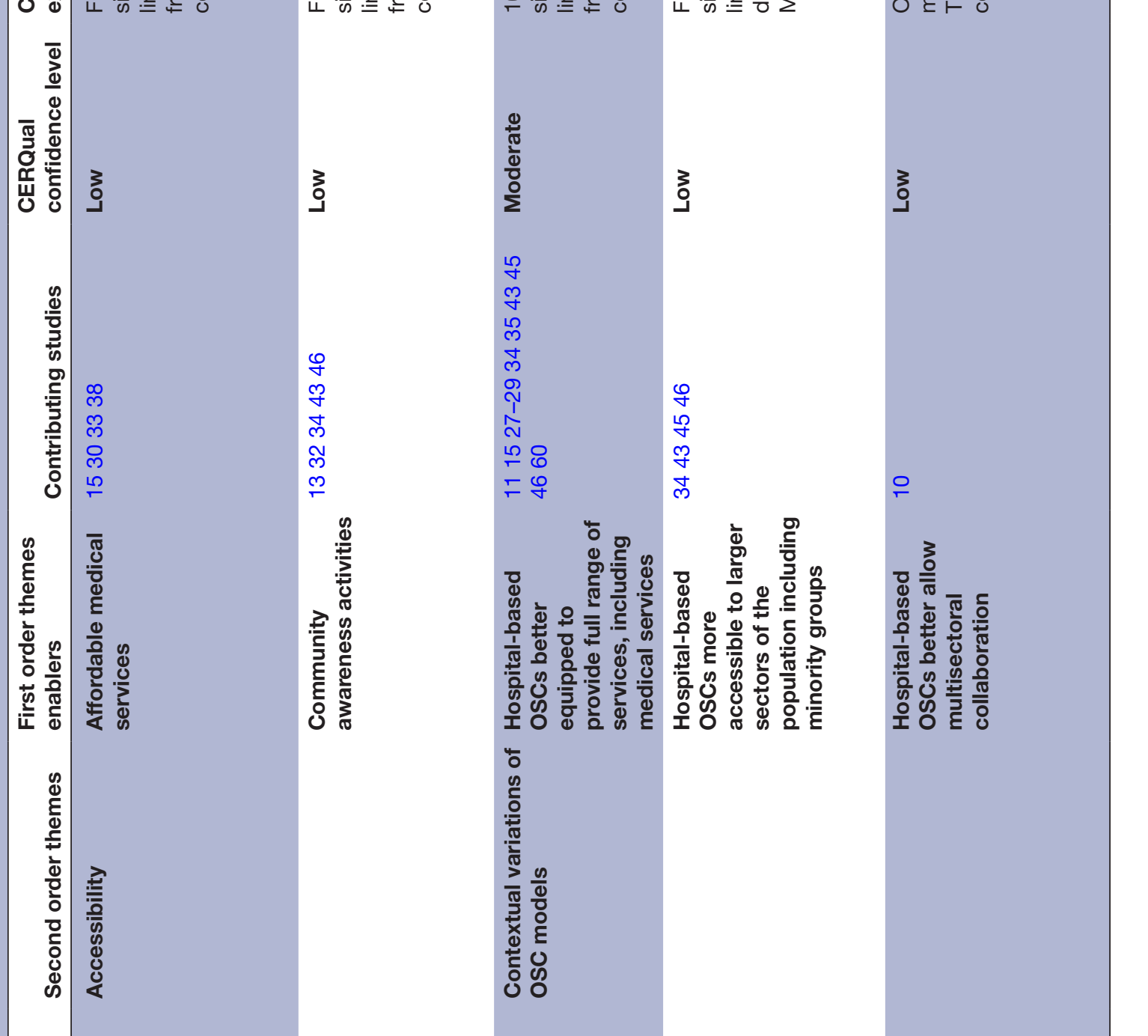

ᄋ̊ำ 


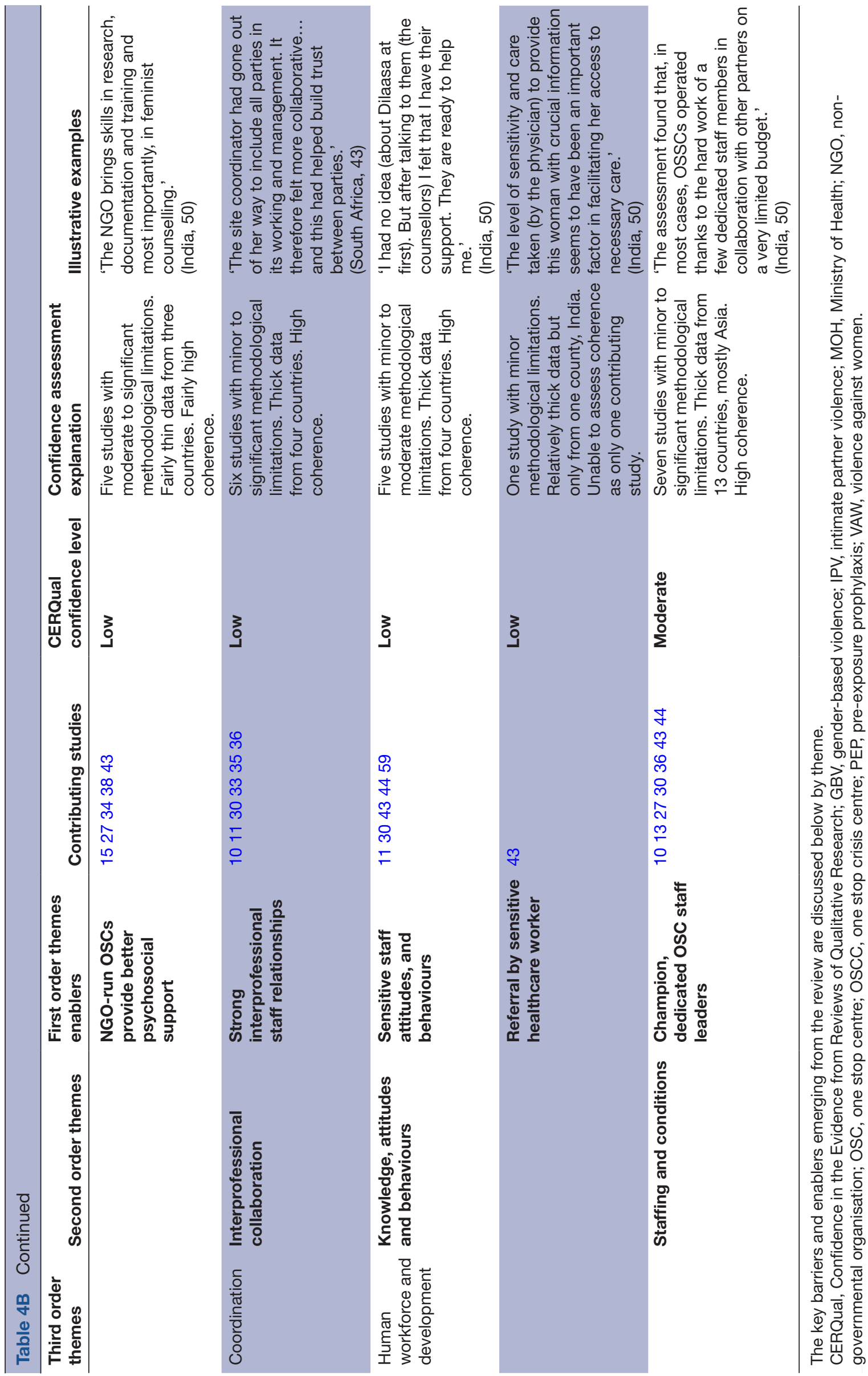

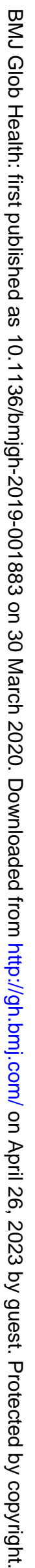


content, contextualisation, availability or visibility within the facility (MC).$^{10-1215163031}$ Conversely, OSCs with SOPs found they enhanced clarity of staff roles, patient flow and referral pathways (MC). ${ }^{10} 14151922$ 28 31-33

\section{Governing bodies}

For some well-established OSCs, regular interagency meetings helped to identify challenges and coordinate responses (MC). ${ }^{10} 1115243033-36$ In two reviews of hospitalbased OSCs in Southeast Asia and one stand-alone centre in South Africa, facility-level advisory committees were ineffective, facing challenges such as lack of participation (lower confidence (LC))..$^{3036} 37$

Some OSCs found that lack of high-level oversight by OSC management led to uncoordinated and delayed services (MC). ${ }^{11} 12172830363839$ OSCs also faced challenges during transitions of ownership (such as from NGO to local government), and many felt transitions were done hurriedly and without clear instructions, resulting in poor accountability and inter-professional staff relationships (LC). ${ }^{35} 3638$

\section{Political will}

Many centres across contexts described 'lack of political will' as a central cause of facility-level challenges (high confidence (HC)). ${ }^{10-13} \quad 15-17283133 \quad 3638-41$ Conversely, executive support, from local managers to national officials, facilitated acceptance of the OSC model (MC). ${ }^{10-121517243033-3542}$

\section{Health system resources \\ Equipment and supplies}

Lack of basic resources was common at OSCs in LMICs, and compromised quality of care (HC). ${ }^{12-14161727283035-38404143}$ Some sexual assault centres reported insufficient basic comfort items like clean clothes and sanitary pads, as well as other basic supplies (HC). ${ }^{172835}$

\section{Information and monitoring}

Poor documentation and data management were seen across contexts (HC). ${ }^{10} 1214152027-29313439404445$ Reasons for this included lack of staff knowledge on how to document violence, outdated information systems, variable record keeping procedures and the ethical and logistical challenges of tracking survivors. A related barrier was lack of evaluation and research; many sites gathered data, but failed to analyse data (HC). ${ }^{10} 13-15$ 28-30 3436394445

\section{Operation costs}

In 17 different countries, the cost to operate OSCs was a significant challenge, seen at both hospital-based and stand-alone OSCs, as well as government-run and NGO-run OSCs (MC). ${ }^{10} 11 \quad 13$ 15-17 28-30 33353645 Some OSCs were forced to weaken or forgo services due to cost, for example, through decreased operation hours, ${ }^{12} 1317222628313335-37414245$ or heavy reliance on volunteers. ${ }^{33353645}$ Some of the evaluation teams intended to conduct cost analyses of OSC, but never did due to lack of resources, capacity and data availability, limiting cost data. A challenge seen in some government-run OSCs was lack of budget planning and transparency, due to issues such as stakeholder disputes (LC). ${ }^{11} 3035-3744$ Some non-profit OSCs faced delayed and sporadic donor disbursement of funds which negatively impacted continuity of care and sustainability (MC). ${ }^{172830353641444647}$

\section{Service delivery}

\section{Quality of care}

In over 14 countries, OSCs of all types were unable to provide adequate psychological support due to lack of trained staff (HC). ${ }^{10} 1416172226$ 28-31 35 38-40 45 46 In some of these situations, untrained volunteers sometimes provided psychosocial support. ${ }^{313345}$ OSCs that provided on-site and trained psychosocial services were better equipped to provide quality care (MC). ${ }^{11} 162830344244$

In 14 reports from 10 countries, OSC operation hours were limited on nights and weekends (HC). ${ }^{12} 13172226283133$ 35-37414245 This was perceived to be a major barrier by survivors, OSC staff and OSC stakeholders across settings, as these are times survivors often faced violence. Long waiting times also restricted access to care at OSCs (MC). ${ }^{141723262730333547}$

At some hospital-based OSCs, health workers failed to provide survivors with important health information, such as pregnancy or sexuallytransmitted infections risk (LC). ${ }^{18} 202328$ Many OSCs were not equipped to provide follow-up services such as long-term counselling or follow-up medical care, which was perceived to be a barrier by survivors and OSC staff in some settings (MC). ${ }^{142830343544}$ At sexual assault centres, minimised points of care was a enabler to adherence and follow-up care, such as providing the full 28-day course of PEP drugs at first visit. (LC). ${ }^{1432}$

\section{Survivor-centredness}

Data from 14 countries demonstrated that OSCs often violated patient confidentiality and privacy, for example, by lack of private consultation rooms (HC). ${ }^{10} 1517202327-31333536394048$ Some OSCs lacked security personnel or systems, and survivors and staff expressed fear for their safety (LC) ${ }^{1728303648}$ Another gap was lack of specific consideration for children and adolescents, for example, by lack of child-friendly environments (LC). ${ }^{161728303345}$ A challenge seen at both hospital-based and stand-alone OSCs was multiple survivor interviews where staff asked similar questions, which could result in secondary victimisation (HC). ${ }^{141727-3033414447}$

\section{Accessibility}

Free services at the OSC facilitated access to survivors (LC). ${ }^{16173033}$ However, 11 reports from OSCs in over 20 countries found that some survivors were forced to pay

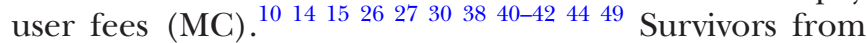
rural areas faced geographical barriers to access at OSCs (MC) ${ }^{18272833354142}$ often due to high cost of transportation (MC). ${ }^{141617273135-3739414445}$ 
At some hospital-based and stand-alone centres, there were negative perceptions of the OSC by the community (LC). ${ }^{16} 2730353642$ Some communities felt OSCs were temporary or had outsider/donor-driven priorities, leading to challenging power dynamics. ${ }^{30} 36$

Thirteen evaluations from 14 countries found that communities were unaware of OSC services, $(\mathrm{HC})^{10151822283036-3842-444750}$ which was linked to low utilisation. ${ }^{10152836384447}$ Awareness raising activities facilitated knowledge of the OSC in some settings, ${ }^{14} 32344245$ although in one study in South Africa, there was low awareness despite multiple community raising efforts. ${ }^{36}$

\section{Location of OSC}

Hospital based-OSCs were found to be better equipped with the infrastructure to provide comprehensive services (MC). ${ }^{10} 12151628343542444551$ In some studies, hospitalbased OSCs were accessible to a larger population, including minority groups, such as those who identified as indigenous or Muslim (LC). ${ }^{34424445}$

Stand-alone were more likely to be known within communities which risked stigmatisation (LG). ${ }^{16} 3347$ Some stand-alone centres were unable to manage the immediate medical needs of survivors due inadequate infrastructure, including inability to provide 24/7 services (LC). ${ }^{16} 2833$ OSCs managed by NGOs, whether at hospital-based or stand-alone centres, were better equipped to provide survivor-centred psychosocial care (LC). ${ }^{1617283442}$

\section{Coordination and collaboration Interprofessional collaboration}

The most common barrier to OSCs, cited in 27 studies, was poor multisector collaboration

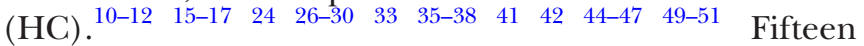
studies reported weak partnerships with police sectors, ${ }^{10} 1626-2830333741424647$ 49-51 eight with legal and justice services, ${ }^{10} 16283038474951$ six with shelters ${ }^{272830424549}$ and five with NGOs. ${ }^{11} 17262930$ Several reports found that OSCs failed to share lessons learnt from implementation with stakeholders (LC). ${ }^{10} 1527283844$ While OSCs were designed to provide all or most services in one location, several evaluations described services as 'fragmented' and the facility as 'not truly one-stop' (MC). ${ }^{12} 163031343847$ Several studies viewed strong interprofessional staff relationships as a enabler (LC). ${ }^{11} 1230333536$

\section{Patient navigation and referrals}

Some OSCs lack signage for confidentiality reasons, and some survivors had difficulty locating services within OSCs (LC) ${ }^{163047}$ Many OSCs noted weak referral networks and lack of referral options (HC). ${ }^{10} 12151628-3034363740464950$ Referrals were especially weak in some primary health centres, where specialists and services were most limited. ${ }^{36}$

\section{Clarity of roles and responsibilities}

Implementing partners often disagreed on OSC priorities, responsibilities and budgets (MC).$^{10111517283033353638}$ At some OSCs, these disputes led to confusion among staff on who and how services should be delivered (LC). ${ }^{1720293035384344}$

\section{Human workforce and development}

Knowledge, attitudes and behaviours

Some health workers at the OSC lacked knowledge on GBV, which was a major barrier, especially in hospital-based OSCs (MC)..$^{30} 34364347$ Some OSC staff lacked knowledge of services available at their facility. ${ }^{10} 15283047$ Many staff held victim-blaming attitudes, such as that survivors solicited attacks by dress or behaviour (HC). ${ }^{14} 172029303441-43$ Some OSC staff behaved insensitively to survivors, for example, by scolding rape survivors (LC) ${ }^{1720414247}$ Many studies found both on-site and off-site police officers to have victim-blaming attitudes, and to mistreat survivors (HC). ${ }^{1617273441424647}$

In hospital-based OSCs, staff with sensitive, nonjudgmental attitudes towards survivors facilitated highquality care (LC). ${ }^{12} 18304243$ In one study, survivors referred to the OSC by sensitive health workers felt encouraged to access the OSC (LC). ${ }^{42}$ At some OSCs, a small number of dedicated 'champion' staff were needed to ensure the OSC continued in the face of unexpected challenges (MC). ${ }^{11} 142830364243$ One study found that when the 'champion' left, the OSC closed or reduced services. ${ }^{14}$

\section{Training and support}

Many OSCs, especially hospital-based centres, provided no training on how to care for survivors (HC), ${ }^{10121630313343}$ and little instruction on OSC policies (HC). ${ }^{10} 12$ 15-17 $202830313334394043-45$ OSCs also lacked mechanisms for sustainable knowledge acquisition such as follow-up trainings ${ }^{3033} 3445$ and evaluation of trainings. ${ }^{30} 45$

\section{Staffing conditions}

Eighteen studies from 15 countries showed that insufficient staff was a barrier across settings (HC). ${ }^{10} 121517$ 26-28 3031 33-37 3941434546 Many OSCs faced staff shortages, ${ }^{10} 12151726-283031$ 34-37 3941434546 and high staff turnover. ${ }^{17} 283033353645$ Some OSCs, especially standalone centres, relied on volunteers to provide essential services such as psychosocial support and trauma counselling. ${ }^{33} 353645$ In one study, survivors who used the OSC felt that staff were not adequately diverse in age and marital status, ${ }^{42}$ while other studies found there to be a lack of female doctors, ${ }^{3041}$ and female police officers. ${ }^{30} 3746$

A common barrier in hospital-based OSCs was increased staff time constraints, as responsibilities at the OSC were in addition to other job requirements (MC). ${ }^{11} 122830343540-4346$ Some OSC staff reported burn-out due to poor health system conditions such as staff shortages (LC). ${ }^{1633434449}$

\section{Thematic synthesis}

The thematic synthesis presented in table 5 provides one framework for understanding where the enablers and barriers operate at various levels of the OSC theory of 
Table 5 Thematic synthesis of barriers and enablers of the OSC model to implementation and achieving intended results

\section{Output level}

\begin{tabular}{|c|c|}
\hline \multirow[t]{3}{*}{$\begin{array}{l}\text { Increased staff trainings } \\
\text { on trauma-informed care }\end{array}$} & $\begin{array}{l}\text { B: Increased healthcare worker time } \\
\text { constraints }{ }^{M}\end{array}$ \\
\hline & B: Harmful staff attitudes on IPV/SV ${ }^{\mathrm{H}}$ \\
\hline & B: Staff burnout ${ }^{\mathrm{L}}$ \\
\hline \multirow[t]{4}{*}{$\begin{array}{l}\text { Reduced number of } \\
\text { survivor interview }\end{array}$} & $\begin{array}{l}\text { E: Standardised policies and } \\
\text { procedures }^{\mathrm{M}}\end{array}$ \\
\hline & $\begin{array}{l}\text { B: Lack of standardised policies and } \\
\text { procedures }{ }^{M}\end{array}$ \\
\hline & $\begin{array}{l}\text { B: Inadequate training on trauma- } \\
\text { informed care and OSC operations }{ }^{H}\end{array}$ \\
\hline & $\begin{array}{l}\text { B: Unclear, uncontextualised or } \\
\text { unavailable OSC policies and } \\
\text { procedures }^{\text {M }}\end{array}$ \\
\hline
\end{tabular}

\section{Outcome level}

(accessibity

\section{Accessibility}

Reduced number of survivor interviews

\section{E: Standardised policies and procedures $^{\mathrm{M}}$}

B: Lack of standardised policies and procedures $^{\mathrm{M}}$

$\mathrm{B}$ : Inadequate training on traumainformed care and OSC operations ${ }^{\mathrm{H}}$

B: Unclear, uncontextualised or unavailable OSC policies and procedures $^{\mathrm{M}}$

\begin{tabular}{|c|c|c|}
\hline \multirow[t]{10}{*}{$\begin{array}{l}\text { More services provided at } \\
\text { one place and all hours }\end{array}$} & $\begin{array}{l}\text { E: Available, on-site psychosocial } \\
\text { services and support }{ }^{\mathrm{M}}\end{array}$ & $\begin{array}{l}\text { E: Sensitive staff attitudes and } \\
\text { behaviours }{ }^{L}\end{array}$ \\
\hline & $\begin{array}{l}\text { B: Lack of basic medical supplies, } \\
\text { facility equipment, survivor comfort } \\
\text { items }{ }^{H}\end{array}$ & E: Sensitive staff referrals ${ }^{\mathrm{L}}$ \\
\hline & B: Insufficient staff ${ }^{\mathrm{H}}$ & $\begin{array}{l}\text { E: Champion, dedicated OSC } \\
\text { staff leaders } \\
M\end{array}$ \\
\hline & B: Lack of psychosocial services ${ }^{H}$ & $\begin{array}{l}\text { B: Failure to provide health } \\
\text { information }{ }^{L}\end{array}$ \\
\hline & B: Lack of security at OSC ${ }^{\mathrm{L}}$ & $\begin{array}{l}\text { B: Harmful behaviours of } \\
\text { healthcare staff towards } \\
\text { survivors } L\end{array}$ \\
\hline & $\begin{array}{l}\text { B: Lack of designated budgets and } \\
\text { budget transparency } L\end{array}$ & B: Mistreatment by police ${ }^{H}$ \\
\hline & $\begin{array}{l}\text { B: Unsustainable, donor-dependent } \\
\text { funding sources }^{M}\end{array}$ & $\begin{array}{l}\text { B: Lack of staff knowledge on } \\
\text { IPV/SV }\end{array}$ \\
\hline & $\begin{array}{l}\text { B: Operation costs not feasible in many } \\
\text { low-resource settings }{ }^{M}\end{array}$ & $\begin{array}{l}\text { B: Lack of long-term support } \\
\text { and follow-up } M\end{array}$ \\
\hline & & $\begin{array}{l}\text { B: Compromised confidentiality } \\
\text { and privacy }{ }^{H}\end{array}$ \\
\hline & & $\begin{array}{l}\text { B: Lack of child friendly } \\
\text { environments }{ }^{\llcorner}\end{array}$ \\
\hline
\end{tabular}

E: Community awareness raising activities ${ }^{\mathrm{L}}$

E: Focal person to assist user with navigation of $\mathrm{OSC}^{\mathrm{L}}$

E: Affordable medical services and support ${ }^{\mathrm{L}}$

E: Minimised points of care for survivors ${ }^{\mathrm{L}}$

B: Transportation cost ${ }^{M}$

B: Lack of rural access ${ }^{M}$

B: Lack of services on night and weekends $^{\mathrm{H}}$

B: Out-of-pocket user costs ${ }^{H}$

B: Long wait times ${ }^{M}$

B: Lack of community awareness ${ }^{\mathrm{H}}$

B: Navigation challenges within facility ${ }^{\mathrm{L}}$

\section{Acceptability}

B: Hostile and sceptical community beliefs ${ }^{\mathrm{L}}$

B: Non-representative staff ${ }^{\mathrm{L}}$ 
Table 5 Continued

\begin{tabular}{|c|c|c|c|}
\hline Output level & & Outcome level & \\
\hline \multirow[t]{10}{*}{$\begin{array}{l}\text { Increased evaluations and } \\
\text { research }\end{array}$} & B: Poor data management systems ${ }^{\mathrm{H}}$ & $\begin{array}{l}\text { Multisectoral } \\
\text { coordination }\end{array}$ & $\begin{array}{l}\text { E: Strong interprofessional staff } \\
\text { relationships }{ }^{L}\end{array}$ \\
\hline & B: Lack of oversight and supervision ${ }^{M}$ & & $\begin{array}{l}\text { E: Regular interagency meetings } \\
\mathrm{M}\end{array}$ \\
\hline & $\begin{array}{l}\text { B: Lack of facility-level monitoring } \\
\text { mechanisms }\end{array}$ & & $\underset{\mathrm{H}}{\mathrm{B}}$ : Weak multi-sectoral networks \\
\hline & & & B: Unclear staff roles ${ }^{\mathrm{L}}$ \\
\hline & & & B: Fragmented services ${ }^{M}$ \\
\hline & & & $\begin{array}{l}\text { B: Poor transfers of } \\
\text { management }{ }^{L}\end{array}$ \\
\hline & & & $\begin{array}{l}\text { B: Lack of information sharing } \\
\text { between sites }{ }^{L}\end{array}$ \\
\hline & & & $\mathrm{B}$ : Weak referral networks ${ }^{\mathrm{H}}$ \\
\hline & & & $\begin{array}{l}\text { B: Unclear responsibilities of } \\
\text { implementing partners }{ }^{M}\end{array}$ \\
\hline & & & $\begin{array}{l}\text { B: Ineffective advisory } \\
\text { committees } L\end{array}$ \\
\hline
\end{tabular}

\footnotetext{
${ }^{\mathrm{H}}$ indicates high-confidence evidence. ${ }^{\mathrm{M}}$ moderate-confidence evidence. ${ }^{\mathrm{L}}$ low-confidence evidence. $\mathrm{F}$, indicates enabler. $\mathrm{E}$, indicates enabler. IPV, intimate partner violence; OSC, one stop centre; SV, sexual violence.
}

change, and includes findings from the qualitative, quantitative and mixed methods studies. Enablers and barriers were found to occur at the output level 19 times and the outcome level 32 times. It is important to note that while specific challenges and enablers have been identified, these findings do not operate in isolation, rather, they interact with and influence each other. ${ }^{60}$ For example, lack of standardised operating procedures affects the ability to achieve the OSC output of decreased number of survivor interviews and serves as a barrier to the OSC outcome of improved quality care. Additionally, many of the identified barriers were due to insufficient inputs/ resources. For instance, OSC budget constraints often lead to insufficient number of staff to provide the desired OSC output of $24 / 7$ services to survivors, which negatively impacted quality of care.

The majority of studies did not compare contextual variations of the OSC model, such as hospital-based versus stand-alone centres. Figure 2 provides a brief overview of the findings from studies that did compare enablers and barriers between various forms of the OSC model. These include the hospital-based OSC, which is typically within

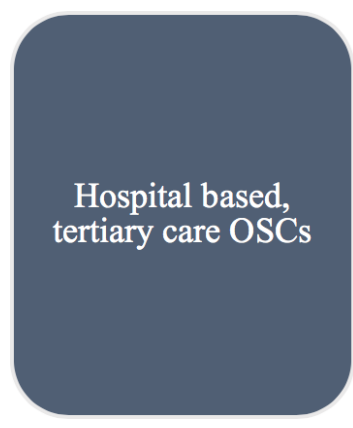

- May be more expensive and less feasible in rural and/or non-teritary care settings $\mathrm{L}$

- May be more accessible to larger sectors of the population including minority groups ${ }^{\mathrm{L}}$

- May allow for better multisectoral collaboration ${ }^{\mathrm{L}}$

- May be better equipped with infrastructure to provide full range of multidisciplinary services ${ }^{M}$

- Can better meet medical needs of survivors ${ }^{M}$

- May decrease emphasis on survivor services from other sectors $\mathrm{L}$

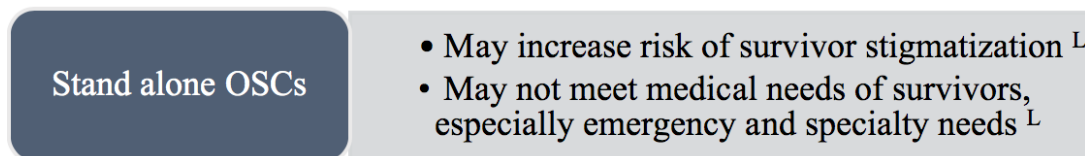

NGO-run OSCs

- May provide better psychosocial support $\mathrm{L}$

- May lack availibility to allow continuity of care ${ }^{\mathrm{L}}$

Figure 2 Contextual variations of the OSC model: a comparison of enablers and barriers. OSC, one stop centre. 
a tertiary care centre, the stand-alone OSC and the OSCrun primarily by NGOs.

\section{DISCUSSION}

This study identified 15 barriers with high-confidence evidence that often prevented the OSC model from being implemented as designed and achieving its intended results. Implementation of the OSC model often faced several barriers including insufficient staffing, basic equipment and sustainable funding which prevented many OSCs from enacting even low-level changes, such as adequate staff trainings on trauma-informed care. With these constraints, the OSC model often faced significant barriers in producing higher-level changes, such as improved multisectoral coordination and accessibility of services. Multiple external factors often hindered implementation and achievement of intended results, such as lack of political will and government investment on issues of IPV. ${ }^{10-13} 15-1728313336$ 38-41 Many of the barriers identified in the OSC model are similar to those identified for services being provided in traditional (non-integrated) models for survivors of violence.

Several findings with moderate-confidence evidence were identified as enabling factors to implementation and achieving intended results, but no enablers with high-confidence evidence were identified. This could be due to the lack of adequate resources/inputs to identify enablers. More rigorous evaluation would help to better elucidate enabling factors.

The findings from this review can help OSC stakeholders, including funders, governments, NGOs and advocacy and policy organisations to identify which factors may be limiting their ability to implement the OSC model and achieve its intended results, and to strategically direct investment in those areas. Prior to further scale-up, the authors recommend that OSC implementers and funders conduct facility appraisals and quality performance assessments to ensure facility preparedness to respond to violence against women with the OSC model. Review findings can also inform the development of a systematic evaluation tool of the OSC model using the theory of change and result-based management framework.

There are several evidence gaps in the contributing studies, most notably, lack of contextual details in the primary studies. Many evaluations reported findings from several types of OSCs without specifying which enablers or barriers may be specific to a particular model. Contextual factors are also essential to understanding the strengths and weaknesses of each model and can inform which model may be better fit in a specific setting.

One disadvantage of the OSC model is that it is often more costly to maintain than other models of integrated care for survivors. ${ }^{101114}$ OSCs require a dedicated staff, spaces and funding streams that may not be feasible in financially constrained and/or rural settings. ${ }^{11} 111315-1728-3033353645$ Other forms of integrated approaches provide multidisciplinary care without these additional costs by integrating coordinated detection and referral into existing services. ${ }^{11}$ Some have argued that it may be more realistic in resource-constrained settings to invest in integrated models of care for survivors that do not require a dedicated or specialised staff and structure, such as the sexual assault response team or the sexual assault nurse examiner approaches used in many Global North contexts. ${ }^{60}$ Concern has also been raised that vertical investment in the OSC model may drive attention and efforts away from a broader health-system based response to violence against women. ${ }^{16}$ Commentators have warned that OSCs may be a poor investment unless they are coupled to broader efforts of system strengthening. ${ }^{16} 60$

The OSC model typically provides care for survivors of IPV and SV, however it may not take into account that specific forms of violence have differing needs. For example, non-partner rape more often requires immediate forensic evidence collection, while partner violence more often requires legal aid for civil matters such as divorce. ${ }^{14}$ Additionally, some OSC did not meet the needs of child and/or adolescent survivors of violence. ${ }^{161728303345}$ These perspectives suggest that the OSC cannot take a 'one size fits all' approach if it is to meet the specific and variable needs of all survivors violence.

The target population of the OSC model and more broadly, the majority of care delivery models for survivors of violence has historically been cis-gender women and has largely excluded LGBTQ (lesbian, gay, bisexual, transgender and queer) survivors. While LGBTQ communities face IPV and SV at alarmingly high rates, much of the IPV/SV response has largely failed to address inequities in care. ${ }^{61}$ Many lesbian, bisexual, trans and gender non-conforming survivors may be excluded, discriminated and revictimised when seeking services for IPV/SV at centres like OSCs.

\section{Strengths and limitations of this review}

It is possible some evaluations were excluded from this review that did not fit our inclusion criteria or the review's operational definition of the OSC. Our study was designed to identify health-system based OSCs and likely does not incorporate similar one-stop programming in the justice sector. The official definition of the OSC has been debated as OSCs vary considerably by region and context. Our search strategies were designed to minimise this weakness by strictly defining the review's operational definition and including as many variations of OSCs as the authors could locate in the literature. Six studies were excluded from this review because they were published in languages other than English, Spanish or French. Authors did not include studies published in Portuguese and may have missed findings of comprehensive service approaches in dedicates spaces in Brazil. Some of the evaluations included were unpublished reports, and 13 studies were found to be low quality. Some of the included studies failed to provide specific data on 
study population, such as recruitment strategy. Methodological quality of each study is reflected in the CERQual assessments. Another potential limitation is that initial coding was performed by one author (RMO), however all resultant themes received input from all members of the research team.

There are multiple important strengths of this review. This review conducted an extensive and systematic search; it analyses data from 42 studies. The review uses the CERQual approach to assess the confidence in the review findings, which gives the review more credibility, reliability and transparency. The review also drew on the experience of multiple global experts in one stop centres who attended the 2018 WHO meeting on one stop centres.

\section{CONCLUSION}

The results of this study demonstrate that the OSC model has often failed to be implemented as designed due to a number of barriers with high-confidence evidence. Until these specific factors are addressed, the OSC model will be unable to achieve what it was designed to accomplish—to provide effective, multidisciplinary, coordinated and survivor-centred care to survivors of intimate partner and sexual violence. Prior to further promotion and scale-up of this model in LMICs, OSC leadership, funders, policymakers, government officials and staff should use the evidence in this review to prioritise and guide investment and to inform more rigorous evaluation of existing OSCs.

\section{Author affiliations}

${ }^{1}$ Department of Medicine, Brigham and Women's Hospital, Boston, Massachusetts, USA

${ }^{2}$ Department of Reproductive Health and Research, WHO, Geneva, Switzerland ${ }^{3}$ Department of Global Health and Development, London School of Hygiene and Tropical Medicine, London, UK

Twitter Rose McKeon Olson @rose_m_olson

Contributors This was submitted in prior submission.

Funding The authors have not declared a specific grant for this research from any funding agency in the public, commercial or not-for-profit sectors.

\section{Competing interests None declared.}

Patient and public involvement Patients and/or the public were not involved in the design, or conduct, or reporting or dissemination plans of this research.

Patient consent for publication Not required.

Provenance and peer review Not commissioned; externally peer reviewed.

Data availability statement All data relevant to the study are included in the article or uploaded as supplementary information.

Open access This is an open access article distributed in accordance with the Creative Commons Attribution Non Commercial (CC BY-NC 4.0) license, which permits others to distribute, remix, adapt, build upon this work non-commercially, and license their derivative works on different terms, provided the original work is properly cited, appropriate credit is given, any changes made indicated, and the use is non-commercial. See: http://creativecommons.org/licenses/by-nc/4.0/.

\section{ORCID iD}

Rose McKeon Olson http://orcid.org/0000-0002-6448-9517

\section{REFERENCES}

1 Campbell JC. Health consequences of intimate partner violence. Lancet 2002;359:1331-6.
2 Heise L, Ellsberg M, Gottemoeller M. Center for health and gender equity (change). ending violence against women. Baltimore: Johns Hopkins University School of Public Health, 1999. https://www. k4health.org/sites/default/files/L11.pdf

3 World Health Organization, London School of Hygiene and Tropical Medicine, South African Medical Research Council. Global and regional estimates of violence against women: prevalence and health effects of intimate partner violence and Non-partner sexual violence against women. Geneva: World Health Organization, 2013. http:// apps.who.int/iris/bitstream/handle/10665/85239/9789241564625_ eng.pdf?sequence $=1$

4 United Nations. Transforming our world: the 2030 agenda for sustainable development. A/RES/70/1. New York: United Nations, 2015. http://www.un.org/millenniumgoals/2014MDGreport/ MDG2014Englishweb.pdf

5 World Health Organization. Health care for women subjected to intimate partner violence or sexual violence: a clinical Handbook. Geneva: World Health Organization, 2014. http://apps.who.int/ iris/bitstream/handle/10665/136101/WHO_RHR_14.26_eng.pdf? sequence $=1$

6 Bonomi AE, Anderson ML, Rivara FP, et al. Health care utilization and costs associated with physical and nonphysical-only intimate partner violence. Health Serv Res 2009;44:1052-67.

7 Koss MP, Koss PG, Woodruff WJ. Deleterious effects of criminal victimization on women's health and medical utilization. Arch Intern Med 1991;151:342-7.

8 Feder GS, Hutson M, Ramsay J, et al. Women exposed to intimate partner violence: expectations and experiences when they encounter health care professionals: a meta-analysis of qualitative studies. Arch Intern Med 2006;166:22-37.

9 Grisurapong S. Establishing a one-stop crisis center for women suffering violence in Khonkaen Hospital, Thailand. Int J Gynaecol Obstet 2002;78 Suppl 1:S27-38.

10 UNFPA Asia and the Pacific Regional Office. Health sector response to gender-based violence: an assessment of the Asia Pacific region. Bangkok: UNFPA Asia and the Pacific Regional Office, 2010. https://asiapacific.unfpa.org/sites/default/files/pub-pdf/Assessment. pdf

11 Keesbury J, Onyango-Ouma W, Undie C, et al. A review and evaluation of multi-sectoral response services ("one-stop centers") for gender-based violence in Kenya and Zambia. Nairobi: Population Council, 2012.

12 Jordaan S, Slaven F, Louwrens C, et al. Thuthuzela care centres compliance audit and gap analysis. Pretoria: Foundation for Professional Development, 2016.

13 Bustelo M, Martinez S, Millard MP, et al. Evaluación de Impacto del Proyecto Ciudad Mujer en El Salvado. San Salvador: Inter-American Development Bank, 2016.

14 Keesbury J, Askew I. Comprehensive responses to gender based violence in low-resource settings: lessons learned from implementation. Lusaka: Population Council, 2010.

15 Colombini M, Ali SH, Watts C, et al. One stop crisis centres: a policy analysis of the Malaysian response to intimate partner violence. Health Res Policy Syst 2011;9:25.

16 Colombini M, Mayhew SH, Ali SH, et al. An integrated health sector response to violence against women in Malaysia: lessons for supporting scale up. BMC Public Health 2012;12:548.

17 Mukwege D, Berg M, A holistic BM. A holistic, person-centred care model for victims of sexual violence in Democratic Republic of Congo: the Panzi Hospital one-stop centre model of care. PLoS Med 2016;13:e1002156.

18 Acebes-Escobal BC, Nerida MC, Chez RA. Abuse of women and children in a Philippine community. Int J Gynaecol Obstet 2002;76:213-7.

19 Buard V, Van den Bergh R, Tayler-Smith K, et al. Characteristics, medical management and outcomes of survivors of sexual genderbased violence, Nairobi, Kenya. Public Health Action 2013;3:109-12.

20 Chew KS, Noredelina MN, Ida ZZ, et al. Knowledge, attitude and practice among healthcare staffs in the emergency department, hospital Universiti Sains Malaysia towards rape victims in one stop crisis centre (OSCC). Med J Malaysia 2015;70:162-8.

21 Harrison RE, Pearson L, Vere M, et al. Care requirements for clients who present after rape and clients who presented after consensual sex as a minor at a clinic in Harare, Zimbabwe, from 2011 to 2014. PLoS One 2017;12:e0184634-18.

22 Ranney ML, Rennert-May E, Spitzer R, et al. A novel ED-based sexual assault centre in Western Kenya: description of patients and analysis of treatment patterns. Emerg Med J 2011;28:927-31.

23 Roos I, Nel M, van Vuuren MVJ. Profile of rape victims treated at the Tshepong victim support centre, National district Hospital, Bloemfontein. S Afr Med J 2006;96:615. 
24 Tien L-C, Wu Y-L, Lin T-W, et al. Different perceptions of interprofessional collaboration and factors influencing the onestop service for sexual assault victims in Taiwan. J Interprof Care 2017;31:98-104.

25 Chiu WK, Lam WC, Chu NH, et al. Sexual violence cases in a hospital setting in Hong Kong: victims' demographic event characteristics, and management. Hong Kong Med $\lrcorner$ 2016;22:567-81.

26 Bairagi G, Chanda BK, Naher N, et al. One stop crisis centre: A model of hospital-based service for domestic violence, burn \& sexual assault survivors in Bangladesh. The ORION 2006;25:407-10.

27 IRC Sierra Leone Programme. Navigating justice: an exploratory study of obstacles facing survivors of sexual violence in Sierra Leone. New York City: International Rescue Committee, 2010.

28 Khorloo E. Assessment report on one stop service centers for victims of violence in Mongolia. Ulaanbaatar, 2018.

29 Chepuka L, Taegtmeyer M, Richards E, et al. Assessment of the capacity of the health sector to respond to violence against women and children in Malawi. Lilongwe: Liverpool School of Tropical Meidcine, 2011

30 UNFPA. Assessment of the performance of the hospital-based one stop crisis management centres. Kathmandu: UNFPA, government of Nepal Ministry of health and population, Nepal health sector report programme, 2013. http://un.info.np/Net/NeoDocs/View/ 3431

31 Ellsberg M, Heilman B, Namy S, et al. Violence against women in Melanesia and Timor-Leste. Canberra: International Center for Research on Women (ICRW), 2008. https://www.usip.org/sites/ default/files/missing-peace/Ellsberg-Mary.pdf

$32 \mathrm{Kim}$ JC, Askew I, Muvhango L, et al. Comprehensive care and HIV prophylaxis after sexual assault in rural South Africa: the Refentse intervention study. BMJ 2009;338:b515.

33 CARE Gender \& Empowerment. One-Stop model of support for survivors of gender-based violence: lessons from care Zambia. Atlanta: CARE, 2013. https://www.care.org/sites/default/files/ documents/GBV-2013-ZMB-CARE-ASAZA-OSC-Case-Study.pdf

34 Sundari Ravindran TK, Undurti V. Dilaasa: evaluation report. Mumbai: Centre for Enquiry into Health and Allied Themes (CEHAT), Municipal Corportion of Mumbai (BMC), 2010. http://www.cehat.org/uploads/ files/Dilaasaevaluationreport2010.pdf

35 Vetten L. "It Sucks"/“It's a Wonderful Service”: Post-rape care and the micro-politics of institutions. Johannesburg: Shukumisa Campaign and ActionAid South Africa, 2015. http://shukumisa. org.za/wp-content/uploads/2017/09/Thuthuzela-Care-CentresShukumisa-Report-2015.pdf

36 Ranchod S, Boezak S. Establishment of one-stop centres to counteract violence against women in Pretoria and Vryburg. Vienna: Independent Evaluation Unit (IEU) of the United Nations Office on Drugs and Crime, 2013. https://www.unodc.org/documents/ evaluation/Independent_Project_Evaluations/2013/Final_Evaluation ZAFS15_19JUNE2013.pdf

37 Solotaroff JL, Pande RP. Violence against women and girls: lessons from South Asia. South Asia development forum. Washington, DC: World Bank, 2014. http://documents.worldbank.org/curated/en/ 578241468113934520/pdf/906000v10PUB0E00Box385314B00 PUBLIC0.pdf

38 Human Rights Watch. Everyone blames me: barriers to justice and support services for sexual assault survivors in India. New York City: Human Rights Watch, 2017. https://www.hrw.org/report/2017/11/08/ everyone-blames-me/barriers-justice-and-support-services-sexualassault-survivors

39 Directorate General of Monitoring and Evaluation, Planning and Development Board, Goverment of Punjab. Evaluation report: Shaheed Benzair Bhutto women centers transferred to government of Punjab. Lahore, 2016.

40 Kilonzo N, Theobald SJ, Nyamato E, et al. Delivering post-rape care services: Kenya's experience in developing integrated services. Bull World Health Organ 2009;87:555-9.
41 Afsana K, Rashid SF, Thurston W. Challenges and gaps in addressing domestic violence in health policy of Bangladesh. Dhaka, Bangladesh: Women's Domestic Violence Health Project, 2005.

42 CEHAT, BMC. The Dilaasa crisis centre for women: counselling impact study. Mumbai: Centre for Enquiry into Health and Allied Themes (CEHAT), Municipal Corportion of Mumbai (BMC), 2004.

43 Colombini M, Mayhew S, Ali SH, et al. "I feel it is not enough..." Health providers' perspectives on services for victims of intimate partner violence in Malaysia. BMC Health Serv Res 2013;13:65.

44 Bernath T, Gahongayire L. Final evaluation of Rwandan government and one un Isange one stop centre. Kigali: One UN partnership (UNICEF, UN Women, and UNICEF), 2013.

45 Morel-Seytoux S, Liveoak C, Mwansa A, et al. USAID/Zambia gender-based violence programming evaluation. Lusaka: United States Agency for International Development, 2010.

46 UNFPA. Bangladesh independent country programme evaluation, 2016. Available: https://www.unfpa.org/sites/default/files/adminresource/CPE Bangladesh.pdf [Accessed Mar 2019].

47 Undie C, Maternowska MC, Mak'anyengo M, et al. Routine screening for intimate partner violence in public health care settings in Kenya: an assessment of acceptability. Nairobi: APHIA II OR Project in Kenya/ Population Council, 2012.

48 Pun KD, Infanti JJ, Koju R, et al. Community perceptions on domestic violence against pregnant women in Nepal: a qualitative study. Glob Health Action 2016;9:31964.

49 Daruwalla N, Fernandez A, Salam J, et al. Conflict, crisis, and abuse in Dharavi, Mumbai: experiences from six years at a centre for vulnerable women and children. PLoS Med 2009;6:e1000088.

50 Lokuge K, Verputten M, Ajakali M, et al. Health services for genderbased violence: Médecins sans Frontières experience caring for survivors in urban Papua New Guinea. PLoS One 2016;11:e0156813.

51 Kilonzo N. Post rape services in Kenya: a situational analysis. Nairobi: Liverpool VCT and CARE Kenya, 2003. http://www.svri.org/ sites/default/files/attachments/2016-07-18/postrapeserviceskenya_ $0 . p d f$

52 Thomas J, Harden A. Methods for the thematic synthesis of qualitative research in systematic reviews. BMC Med Res Methodol 2008;8:45.

53 Braun V, Clarke V. Using thematic analysis in psychology. Qual Res Psychol 2006;3:77-101.

54 Lewin S, Booth A, Glenton C, et al. Applying GRADE-CERQual to qualitative evidence synthesis findings: introduction to the series. Implement Sci 2018;13:2.

55 Critical Appraisal Skills Programme. CASP qualitative checklist 2018. Available: https://casp-uk.net/wp-content/uploads/2018/01/ CASP-Qualitative-Checklist-2018.pdf [Accessed Mar 2019].

56 von Elm E, Altman DG, Egger M, et al. The strengthening the reporting of observational studies in epidemiology (STROBE) statement: guidelines for reporting observational studies. Int J Surg 2014;12:1495-9.

57 Tong A, Flemming K, Mclnnes E, et al. Enhancing transparency in reporting the synthesis of qualitative research: ENTREQ. BMC Med Res Methodol 2012;12:181.

58 Moher D, Liberati A, Tetzlaff J, et al. Preferred reporting items for systematic reviews and meta-analyses: the PRISMA statement. PLoS Med 2009;6:e1000097.

59 Liberati A, Altman DG, Tetzlaff J, et al. The PRISMA statement for reporting systematic reviews and meta-analyses of studies that evaluate health care interventions: explanation and elaboration. PLoS Med 2009;6:e1000100.

60 Colombini M, Dockerty C, Mayhew SH. Barriers and facilitators to integrating health service responses to intimate partner violence in low- and middle-income countries: a comparative health systems and service analysis. Stud Fam Plann 2017;48:179-200.

61 Ard KL, Makadon HJ. Addressing intimate partner violence in lesbian, gay, bisexual, and transgender patients. J Gen Intern Med 2011;26:930-3 